\title{
Stratospheric Gravity Wave Products from Satellite Infrared Nadir Radiances in the Planning, Execution, and Validation of Aircraft Measurements during DEEPWAVE
}

\author{
STEPHEN D. ECKERMANN \\ Space Science Division, U.S. Naval Research Laboratory, Washington, D.C. \\ James D. Doyle, P. Alex Reinecke, And Carolyn A. Reynolds \\ Marine Meteorology Division, U.S. Naval Research Laboratory, Monterey, California \\ RONALD B. SMITH \\ Yale University, New Haven, Connecticut \\ DAVID C. FRITTS \\ GATS Inc., Boulder, Colorado \\ ANDREAS DÖRNBRACK \\ German Aerospace Center, Oberpfaffenhofen, Germany
}

(Manuscript received 21 January 2019, in final form 27 June 2019)

\begin{abstract}
Gravity wave perturbations in $15-\mu \mathrm{m}$ nadir radiances from the Atmospheric Infrared Sounder (AIRS) and Cross-Track Infrared Sounder (CrIS) informed scientific flight planning for the Deep Propagating Gravity Wave Experiment (DEEPWAVE). AIRS observations from 2003 to 2011 identified the South Island of New Zealand during June-July as a "natural laboratory" for observing deep-propagating gravity wave dynamics. Near-real-time AIRS and CrIS gravity wave products monitored wave activity in and around New Zealand continuously within 10 regions of scientific interest, providing nowcast guidance and validation for flight planners. A novel technique used these gravity wave products to validate upstream forecasts of nonorographic gravity waves with 1-2-day lead times, providing time to plan flight intercepts as tropospheric westerlies brought forecast source regions into range. Postanalysis verifies the choice of $15 \mu \mathrm{m}$ radiances for nowcasting, since $4.3-\mu \mathrm{m}$ gravity wave products yielded spurious diurnal cycles, provided no altitude sensitivity, and proved relatively insensitive to deep gravity wave activity over the South Island. Comparisons of DEEPWAVE flight tracks with AIRS and CrIS gravity wave maps highlight successful repeated vectoring of the aircraft into regions of deep orographic and nonorographic gravity wave activity, and how background winds control the amplitude of waves in radiance perturbation maps. We discuss how gravity wave information in AIRS and CrIS radiances might be directly assimilated into future operational forecasting systems.
\end{abstract}

\section{Introduction}

Gravity waves are ubiquitous features of the atmosphere. Although their major sources are tropospheric, some of these waves propagate into the stratosphere, mesosphere, and thermosphere where, in response to density decreases with height, amplitudes increase,

\footnotetext{
Corresponding author: Stephen D. Eckermann, stephen.eckermann@ nrl.navy.mil
}

leading to progressively larger impacts. Growth of amplitudes with height, for example, leads to wave breaking and deposition of energy and momentum into the flow as dynamical heating and body forcing, respectively. Semicontinuous breaking of gravity waves around the globe sustains planetary-scale forces that drive largescale circulations and climate. Wave breaking is also the dominant source of turbulence and vertical mixing throughout the stratosphere, mesosphere and lower thermosphere. In these and other ways, gravity waves affect 
weather and climate at all altitudes and across scales (Fritts and Alexander 2003).

Gravity waves exist over a broad range of horizontal wavelengths $\left(\lambda_{h} \sim 5-1000 \mathrm{~km}\right)$, while breaking is seeded by subwavelength instabilities that form at unstable wave phases (Andreassen et al. 1998). Current weather and climate models typically run at horizontal gridpoint resolutions of $\sim 10-100 \mathrm{~km}$, approaching a so-called gray zone (e.g., Vosper et al. 2016) where long-wavelength gravity waves are resolved explicitly, but the net drag effects of smaller-scale waves on the resolved flow require parameterization (Kim et al. 2003). Despite decades of research, vigorous debate persists about the relevant dynamical processes controlling instabilities within the gravity wave spectrum that lead to energy and momentum deposition, a situation reflected in disparate dynamics underpinning different gravity wave drag parameterizations currently implemented within weather and climate models (see, e.g., Table S9 of Morgenstern et al. 2017).

These uncertainties arise in part from an inability to observe gravity wave dynamics in sufficient detail to constrain key dynamical aspects of the parameterizations (Alexander et al. 2010). Satellite remote sensors, for example, suffer similar resolution constraints to global models, resolving only longer-wavelength components of the gravity wave spectrum (Wu et al. 2006). These gaps motivated a Deep Propagating Gravity Wave Experiment (DEEPWAVE; Fritts et al. 2016) to acquire the most intensive observations to date of gravity wave generation, propagation and breakdown through deep layers of the atmosphere (see Fig. 2 of Fritts et al. 2016), using instruments on the National Science Foundation (NSF)/National Center for Atmospheric Research (NCAR) Gulfstream V research aircraft (NGV; Laursen et al. 2006).

Yet this very lack of observational knowledge about gravity waves that spurred DEEPWAVE also complicated logistical planning for an NGV-based gravity wave measurement campaign: for example, identifying the best site and time of year; designing near-real-time flightplanning strategies to locate, intercept, and observe specific aspects of gravity wave dynamics; and assessing whether executed flights achieved their requisite science goals. Stratospheric gravity waves observed by infrared nadir sensors, such as the Atmospheric Infrared Sounder (AIRS) on NASA's Aqua satellite, proved pivotal in these and other areas. This paper describes that work, focusing in particular on new and innovative uses of operational near-real-time radiances, used successfully for the first time during DEEPWAVE, which could find future uses in field campaigns and other applications.

Section 2 describes our suite of stratospheric gravity wave products based on infrared nadir satellite imagery.
Section 3 describes how we used these products to plan the experiment, including site selection and a flightplanning "dry run" one year before DEEPWAVE. Section 4 provides examples of how these products were employed as a "nowcast" flight-planning aid during the DEEPWAVE field deployment. Section 5 assesses this effort with reference to executed flight plans and other postmission science studies. Section 6 summaries the major conclusions that arose from this exercise, discusses ways in which future efforts can build upon the experience gained, and contemplates ways in which this gravity wave information from operational satellites could ultimately be assimilated directly by numerical weather prediction (NWP) systems.

\section{Stratospheric gravity wave products}

We isolate gravity wave perturbations in infrared nadir radiance imagery as follows (details are provided in appendix A). For a given channel $i$ of a nadir-viewing instrument measuring narrowband infrared atmospheric emission at a central frequency $\nu_{i}$, we use the Planck blackbody relation to convert the Level $1 b$ (L1B) radiances $R_{\nu_{i}}$ into equivalent brightness temperatures,

$$
T_{B_{i}}=\frac{\alpha_{2} \nu_{i}}{\log \left(\alpha_{1} \nu_{i}^{3} / R_{\nu_{i}}+1\right)},
$$

where $\alpha_{1}=2 h c^{2}, \alpha_{2}=h c / k_{B}, h$ is the Planck constant, $k_{B}$ is the Boltzmann constant, and $c$ is speed of light. By removing frequency dependence, this process allows us to coherently average brightness temperature maps from different channels $i$ with similar kernel functions, as

$$
T_{B_{j}}=\left(n_{j}^{\mathrm{tot}}\right)^{-1} \sum_{n=1}^{n_{j}^{\mathrm{tot}}} T_{B_{i(n)} .}
$$

Gravity wave perturbations $T_{B_{j}}^{\prime}$ are extracted from $T_{B_{j}}$ imagery by fitting and removing the larger-scale background structure using algorithms described in appendix A, section c. Products so derived for DEEPWAVE from specific nadir satellite sensor data are now described.

\section{a. AIRS 15- $\mu \mathrm{m}$ products}

AIRS has observed the atmosphere from NASA's Aqua polar orbiter essentially continuously since mid-2002 (Pagano et al. 2012; Parkinson 2013). Its $1.1^{\circ}$ field of view (FOV) is scanned cross track in a cycle of 90 consecutive step-and-stare measurements separated by $1.1^{\circ}$ and distributed symmetrically about nadir. At the $705-\mathrm{km}$ orbit altitude, these FOVs yield horizontal surface footprint diameters in the along- and cross-scan directions of $\sim 13.5 \times 13.5 \mathrm{~km}^{2}$ at nadir and $\sim 41 \times 22 \mathrm{~km}^{2}$ at the far 

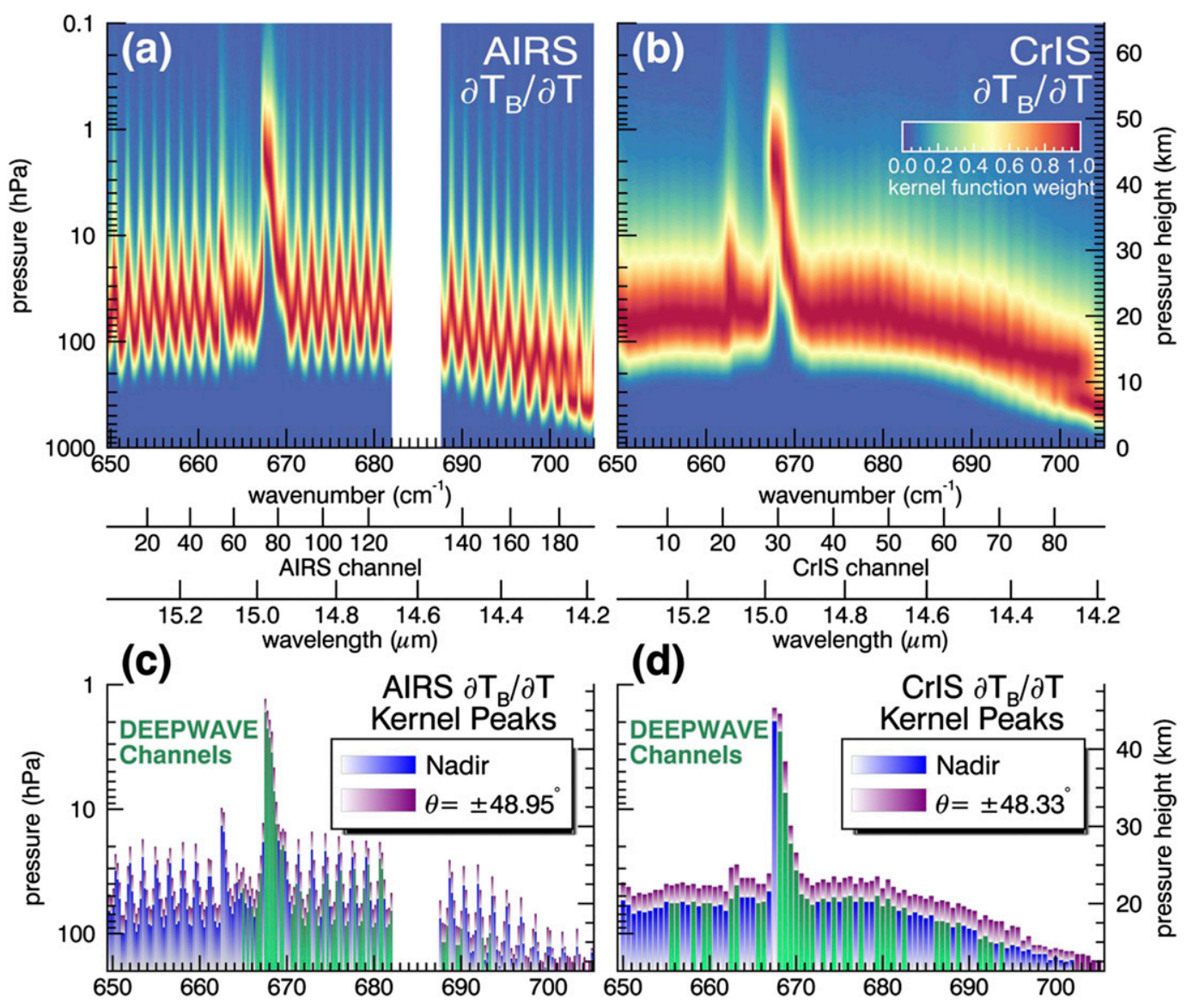

(d)

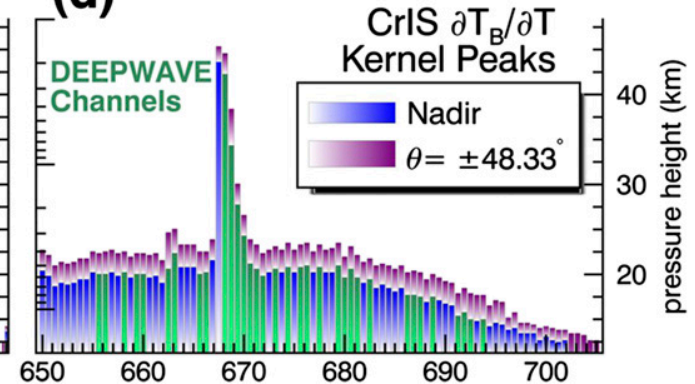

FIG. 1. (top) Kernel functions $\mathscr{K}_{i}(z)=\partial T_{B} / \partial T$ as a function of wavenumber and pressure near the $15 \mu \mathrm{m}$ band for (a) AIRS and (b) CrIS. All functions have been normalized to peak values of unity. (bottom) Location of $\mathscr{K}_{i}(z)$ peaks for nadir (blue) and far off-nadir scan angles (purple) for (c) AIRS and (d) CrIS, with channel subsets used for gravity wave detection marked in green (see Tables A1 and A2).

off-nadir scan angles of $\pm 48.95^{\circ}$, and the scan cycle yields cross-track swath widths of $\sim 1750 \mathrm{~km}$ at the ground $(\sim 5 \%$ smaller for stratospheric observations). These FOVs limit detection to gravity waves of horizontal wavelength $\lambda_{h} \gtrless$ $30-40 \mathrm{~km}$ near the center and $\geqslant 50-100 \mathrm{~km}$ near the edges of the push-broom swath imagery.

The AIRS spectrometer acquires radiances within 2378 frequency intervals (channels) spanning 3.7-15.4 $\mu \mathrm{m}$ (Aumann et al. 2003). In the temperature-sensitive 15 and $4.3 \mu \mathrm{m} \mathrm{CO}$ bands, gravity waves can be imaged in radiance imagery from selected channels where emission peaks in the stratosphere (in the troposphere, cloud contributions swamp any small gravity wave signals). Each infrared band has different advantages and disadvantages for gravity wave detection [see, e.g., appendix A of Gong et al. (2015)]. For DEEPWAVE we focused on $15-\mu \mathrm{m}$-band channels, since (i) kernel functions are narrower vertically, providing greater sensitivity to short vertical wavelengths (see appendix B) and to vertical variations in gravity wave activity [cf. Figs. $3 a$ and $3 b$ of Hoffmann and Alexander (2009)]; (ii) radiative transfer (RT) is simpler. Kernel functions in the $4.3 \mu \mathrm{m}$ band, by contrast, are broader vertically and RT is complicated by breakdown of local thermodynamic equilibrium (LTE; DeSouza-Machado et al. 2007; Hoffmann and Alexander 2009; Chen et al. 2013). Corresponding $4.3 \mu \mathrm{m}$ gravity wave products are described in section $2 \mathrm{c}$ and are compared to our primary $15 \mu \mathrm{m}$ products in section 5 .

Figure 1a plots temperature kernel functions $\mathscr{K}_{i}(z)$ derived for AIRS channels $i=1-194$, spanning the $649.6-705 \mathrm{~cm}^{-1}$ wavenumber range, based on RT calculations for mean austral winter conditions over New Zealand as described in appendix A. Peak values have been normalized to unity to aid intercomparison. Figure 1c beneath it plots histograms of the peak pressure altitude of $\mathscr{K}_{i}(z)$ at the nadir (blue) and far off-nadir (purple) scan angles, the latter peaking higher due to the limb effect.

The subset of 50 AIRS channels used for DEEPWAVE is marked in green in Fig. 1c. As summarized in appendix A, section a, and Table A1, raw brightness temperatures 


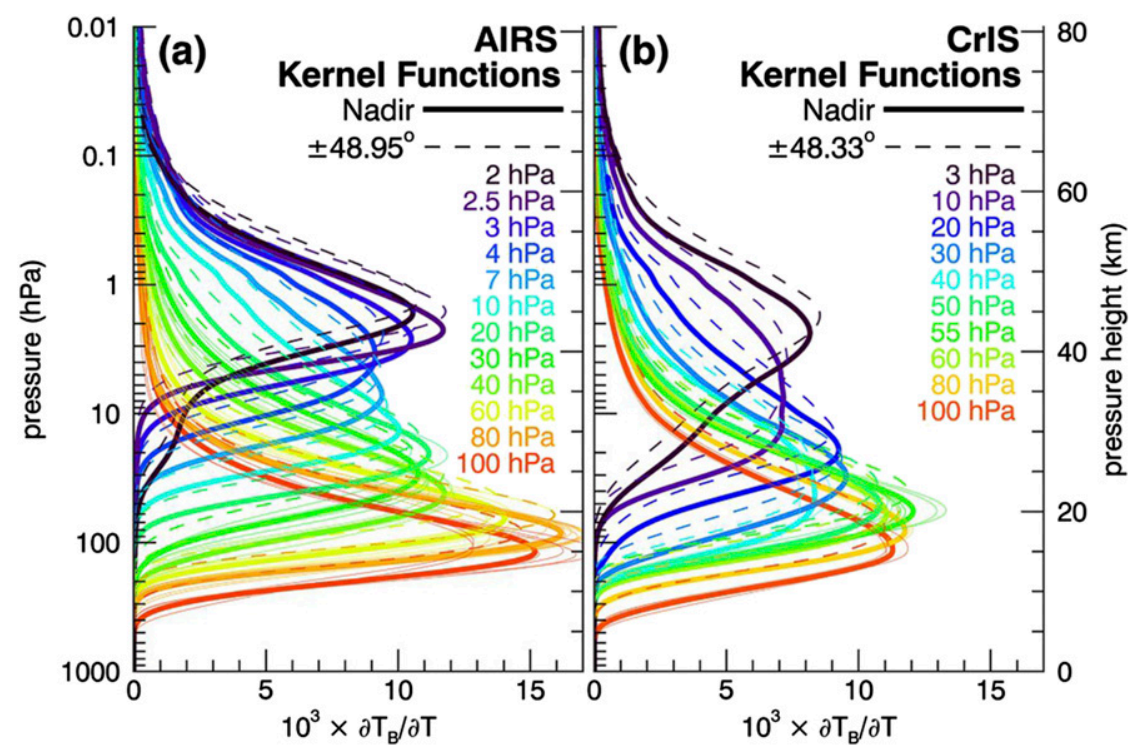

FIG. 2. Thick lines show mean kernel functions $\tilde{\mathscr{K}}_{j}(z)$ at zenith (solid) and far off-nadir (dashed) scan angles for (a) AIRS (channels $8 \beta$ and $9 \beta$ omitted for clarity) and (b) CrIS. Zenith weighting functions $\mathscr{K}_{j}(z)$ for individual channels contributing to these means are shown with thin solid lines.

$T_{B_{i}}$ from these 50 channels were coherently averaged via (2) into a set of $j=1, \ldots, 12$ brightness-temperature scenes $T_{B_{j}}$ with reduced noise to aid gravity wave detection. Their kernel functions are approximated as in (2) as the mean of the contributing channel kernel functions

$$
\tilde{\mathscr{K}}_{j}(z)=\left(n_{j}^{\text {tot }}\right)^{-1} \sum_{n=1}^{n_{j}^{\text {tot }}} \mathscr{K}_{i(n)}(z),
$$

and are plotted as thick solid (dashed) curves in Fig. 2a for the nadir (far off-nadir) views. Thin lines in Fig. 2a show $\mathscr{K}_{i}(z)$ of the 50 individual AIRS channels. These $\tilde{\mathscr{K}}_{j}(z)$ reveal how these 12 channels provide altitude sensitivity over the 100-2 hPa range.

Two AIRS data streams were used to create DEEPWAVE stratospheric gravity wave products. Standard (STND) fields used science-quality version 5 (V5) L1B geolocated radiances issued by the NASA Goddard Earth Sciences Data and Information Services Center (GES DISC), generally within 8-72 h of acquisition. These formed the basis for all pre- and postmission scientific analysis. During the field campaign we also used near-real-time (NRT) V5 L1B fields from NASA's Land Atmosphere NRT Capability for EOS (LANCE; Murphy et al. 2015), which generally appeared on the GES DISC $\leqslant 3 \mathrm{~h}$ after acquisition. NRT radiances contain geolocation errors due to less accurate ephemeris and attitude data, and radiance calibration errors due to lack of space-view fields at times of recent outages [see section 3.2.2.2 of Murphy et al. (2015)]. The former yields very small location errors (typically much smaller than footprint diameters), while the latter is infrequent, small (typically $\sim 0.1 \mathrm{~K}$ ) and has little net impact on gravity wave products, which remove large-scale radiance structure to isolate perturbations. Comparisons in section $4 \mathrm{~b}$ between gravity wave perturbations derived from STND and NRT radiances over the entire 2014 DEEPWAVE austral winter reveal imperceptible differences.

\section{b. CrIS 15- $\mu m$ products}

Leading into the 2014 field campaign, AIRS was entering its 12 th year of operation, well beyond its nominal 5-6-yr design life, with many detectors having failed and been replaced by backups, and other channels exhibiting degraded performance (Pagano et al. 2012; Parkinson 2013). To insure against partial or even total loss of AIRS data during DEEPWAVE, we developed a backup NRT satellite gravity wave product using radiances from the Cross-Track Infrared Sounder (CrIS) on the Suomi National Polar-Orbiting Partnership (NPP) satellite that launched on October 2011 as the first stage of the Joint Polar Satellite System (JPSS; Goldberg et al. 2013).

Similar to AIRS, CrIS observes the atmosphere in 90 FOVs distributed cross track and symmetrically about nadir. CrIS differs from AIRS in that 9 separate FOVs within the so-called CrIS ellipse or field of regard (FOR; Han et al. 2013) acquire data simultaneously during each stare step. Individual FOVs are $\sim 0.963^{\circ}$ in diameter and are separated from adjacent FOVs within the FOR ellipse by $1.1^{\circ}$ (see Fig. 3 of Han et al. 2013). The scan cycle 
consists of 30 step-and-stare FOR measurements in successive $3.33^{\circ}$ scan steps spanning $\pm 48.33^{\circ}$ about nadir, yielding cross-track swaths of $\sim 2200 \mathrm{~km}$ diameter at the ground. For comparison, ground locations of AIRS and CrIS FOVs during an ascending overpass of New Zealand are shown in Fig. 3.

Figures $1 \mathrm{~b}$ and $1 \mathrm{~d}$ plot the normalized CrIS kernel functions and their peak pressure levels, respectively, over the same spectral band used for AIRS in Figs. 1a and 1c. Comparisons reveal that the broader bandwidth of individual CrIS channels reduces the height variability of peak emission across channels relative to AIRS, most noticeably in the $10-100 \mathrm{hPa}$ range.

Green histograms in Fig. 1d mark the 34 individual channels chosen for coherent averaging via (2) into a set of $j=1, \ldots, 10$ brightness-temperature scenes $T_{B_{j}}$ for deriving gravity wave products: see appendix $\mathrm{A}$, section $\mathrm{b}$ and Table A2 for details. The broader CrIS channel bandwidths translate into channel kernel functions in Fig. $2 \mathrm{~b}$ that are broader and less sharply peaked vertically than those for AIRS in Fig. 2a. The mean CrIS kernel functions in Fig. 2b also reveal less altitude coverage of peaks and smaller peak sensitivities. On the other hand, broader bandwidth, longer integration times, and smaller detector noise all combine to yield significantly lower noise levels in individual CrIS $15 \mu \mathrm{m}$ channels relative to AIRS (Zavyalov et al. 2013). Thus reduced sensitivity of CrIS to shorter vertical wavelength gravity waves (see appendix B) is offset to some extent by generally lower noise floors for gravity wave detection relative to AIRS.

\section{c. AIRS and CrIS 4.3- $\mu$ m products}

For cross-validation with our primary $15 \mu \mathrm{m}$ gravity wave products, we also studied gravity waves at $4.3 \mu \mathrm{m}$. For AIRS, following Hoffmann et al. (2013), we coherently averaged $T_{B}$ from 42 individual channels, 26 (channels 2040-2065) spanning $2322.64-2345.95 \mathrm{~cm}^{-1}$ and 16 (channels 2072-2087) spanning 2352.56-2366.86 $\mathrm{cm}^{-1}$. Channels 2066-2071 were omitted since our $\mathscr{K}_{i}(z)$ at these wavelengths revealed sharp local maxima at $\sim 20-30 \mathrm{hPa}$ that departed from the near-constant sensitivity from $\sim 30-50 \mathrm{~km}$ altitude for the other channels [see also Fig. 3b of Hoffmann and Alexander (2009)]. For CrIS we coherently averaged $T_{B}$ from channels $1214-1223\left(2322.5-2345.0 \mathrm{~cm}^{-1}\right)$ and 1226-1231 (2352.5-2365.0 $\left.\mathrm{cm}^{-1}\right)$ to cover similar wavelength bands to AIRS and thus facilitate intercomparisons with the gravity waves seen in AIRS at $4.3 \mu \mathrm{m}$.

\section{Premission planning}

\section{a. Site selection}

To target an ideal site and time of year for DEEPWAVE NGV measurements, 9 years of AIRS $15 \mu \mathrm{m}$ STND
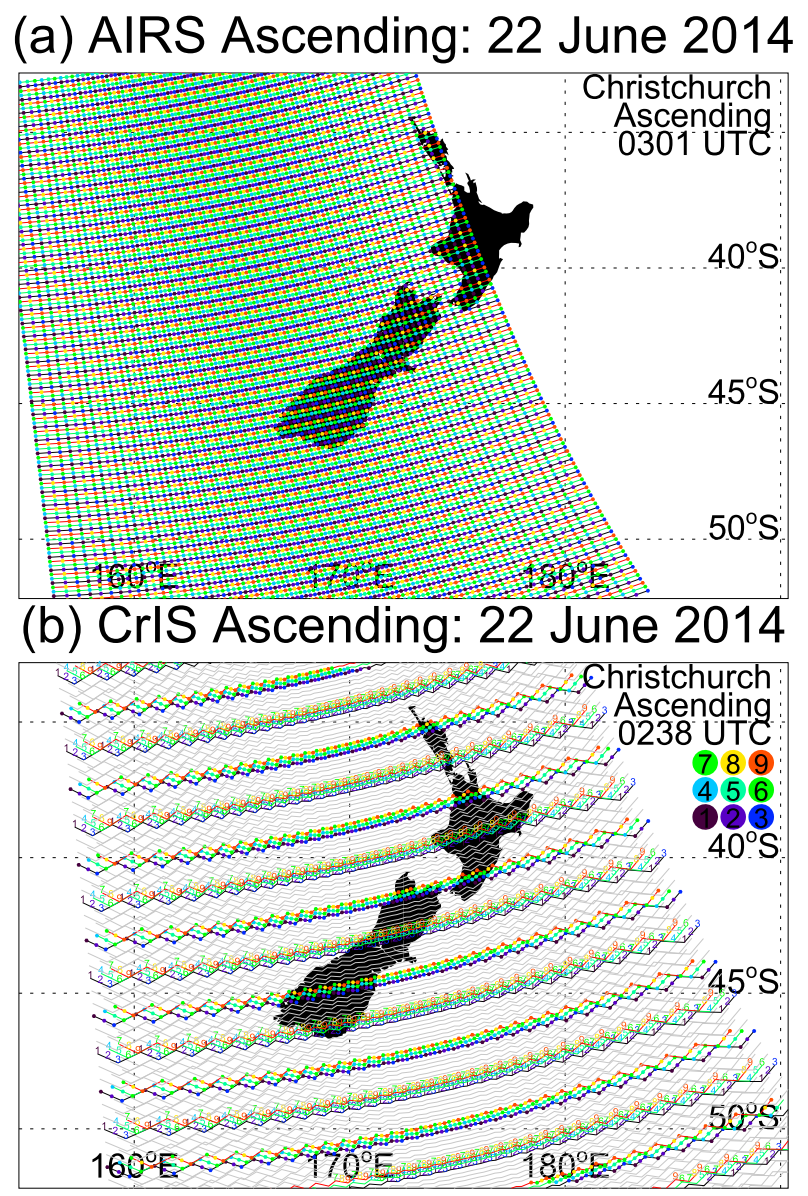

FIG. 3. Ground locations of (a) AIRS and (b) CrIS FOVs during ascending overpasses of New Zealand on 22 Jun 2014. The 9 individual CrIS FOVs in (b), comprising the CrIS FOR ellipse (labeled numerically and by color in legend top right), are color coded on every third scan and labeled on every sixth scan to show rotation of the FOR ellipse with scan angle [see Fig. 3 of Han et al. (2013)]: intervening scans are plotted in gray.

$T_{B_{j}}^{\prime}$ (years 2003-11) were processed into rms values, hereafter denoted $\sigma_{T_{B}}$, to form climatologies that were studied around the globe. The science team focused on winter midlatitudes, where westerly flow from the surface to the mesosphere and lower thermosphere (MLT) potentially allows gravity waves to propagate to high altitudes (Fritts et al. 2016). While the Northern Hemisphere (NH) offered simpler NGV logistics, it was ruled out scientifically, since a similarly motivated NH field experiment was heavily compromised by a stratospheric sudden warming, which reversed stratospheric flow to easterly, enhanced critical-level filtering and allowed few gravity waves to propagate into the MLT (Goldberg et al. 2006). By contrast, the Southern Hemisphere is characterized by a relatively more stable winter vortex with strong uniform vortex-edge westerlies (Shiotani et al. 1993; Roscoe et al. 2005), providing a relatively more propitious 
midlatitude environment for observing deep gravity wave dynamics throughout the austral winter.

Regions around the southern tip of South America, Drake Passage, and Antarctic Peninsula have been identified in a wide variety of high-resolution stratospheric satellite observations as the planetary "hot spot" for deep gravity wave activity during austral winter (e.g., Eckermann and Preusse 1999; McLandress et al. 2000; $\mathrm{Wu}$ et al. 2006; Preusse et al. 2006). Since AIRS $\sigma_{T_{B_{i}}}$ climatologies also show this clearly (see, e.g., Hoffmann et al. 2013; Hendricks et al. 2014), southern South America was initially chosen as the site for a planned field deployment. However, severe local winter weather, air-traffic-control problems, and inadequate local infrastructure eventually led this region to be declared logistically infeasible for an NGV deployment. This in turn spurred further investigation of the AIRS gravity wave climatologies, eventually leading to Christchurch, New Zealand, being selected as the operating base for a DEEPWAVE NGV deployment. We present a selection of the climatological AIRS-based research that informed this choice.

Figs. $4 \mathrm{a}$ and $4 \mathrm{~b}$ show terrain and regional landmarks in and around New Zealand and over the Southern Ocean. Plots below show $\sigma_{T_{B_{j}}}$ derived from 3 and $80 \mathrm{hPa}$ AIRS radiances, averaged throughout June and July from 2003 to 2011. The $80 \mathrm{hPa} \sigma_{T_{B_{j}}}$ in Figs. $4 \mathrm{e}$ and $4 \mathrm{f}$ is enhanced to the north and south of New Zealand, latitudes where the subtropical and midlatitude jets, respectively, attain peak wind speeds (see Eckermann and $\mathrm{Wu}$ 2012; Hendricks et al. 2014). Stronger winds at these latitudes refract gravity waves to longer vertical wavelengths $\lambda_{z}$, making them easier for AIRS to detect (see appendix B) and leading to larger $\sigma_{T_{B}}$ values. Within this general meridional variation, localized hot spots of activity are associated with mountainous terrain. Over Australia, enhanced $80 \mathrm{hPa} \sigma_{T_{B_{j}}}$ in Fig. 4e arises due to orographic gravity waves from the Great Dividing Range, the Flinders Ranges, and the mountains of Tasmania (Eckermann and $\mathrm{Wu}$ 2012). Over New Zealand, $\sigma_{T_{B_{j}}}$ in Fig. $4 \mathrm{e}$ is enhanced along the Southern Alps, and also along the southern coast of the North Island due to a chain of mountain ranges, from the Tararua Range in the far south to the Raukumara Range in the far northeast. Farther to the south, localized hot spots in Fig. 4f are evident over the tiny subantarctic terrain of Young, Buckle, and Sturge Islands, and over the Usarp and Bower Mountains of Antarctica.

At $3 \mathrm{hPa}$ the $\sigma_{T_{B_{j}}}$ maps change. The northernmost enhancements seen at $80 \mathrm{hPa}$ disappear due to weakening winds (see Eckermann and Wu 2012): $\sigma_{T_{B_{j}}}$ is now strongly enhanced over Tasmania and New Zealand. Localized orographic gravity wave enhancements are also still seen over Young, Buckle, and Sturge Islands, and over coastal Antarctic mountain ranges. A new orographic enhancement is observed over the Auckland Islands, which eventually spurred a dedicated NGV research flight during DEEPWAVE (Pautet et al. 2016; Eckermann et al. 2016). A broader increase in $3 \mathrm{hPa}$ $\sigma_{T_{B_{j}}}$ also occurs over the Southern Ocean due to nonorographic gravity waves.

The wealth of diverse deep gravity wave activity evident in AIRS $\sigma_{T_{B_{i}}}$ maps identified New Zealand as a promising base for NGV operations. Based on many science questions that DEEPWAVE was designed to answer (Fritts et al. 2016), 10 geographic subregions were identified next for additional study, as labeled in Figs. $4 \mathrm{c}-\mathrm{f}$.

Time series of $\sigma_{T_{B_{3}}}$ from May through August, averaged from 2003 to 2011 at three altitudes within three of these geographic subregions, are plotted in Fig. 5. Here $3 \times 3$ FOV smoothing of $T_{B_{j}}^{\prime}$ swath imagery was performed prior to averaging to improve signal to noise. Green curves in Fig. 5 show the means and \pm 1 standard deviations, while gray curves show maximum and minimum values. These climatologies reveal preferred periods of enhanced deep wave activity at all locations. Over the South Island and Tasmania, $\sigma_{T_{B_{j}}}$ peaks in midJune through mid-July, whereas $\sigma_{T_{B_{j}}}$ in the Southern Ocean west region increases through June and July, eventually peaking during August.

These combined $\sigma_{T_{B_{j}}}$ data led the science team to propose the South Island of New Zealand (Christchurch International Airport; $43.49^{\circ} \mathrm{S}, 172.54^{\circ} \mathrm{E}$ ) as the operating base for DEEPWAVE NGV field measurements during a period within June-July of 2014. Final dates of the NGV deployment (6 June-21 July) are marked in blue in Fig. 5, and clearly encapsulate times of enhanced gravity wave activity at specific locations and altitudes of scientific interest.

\section{b. Flight planning “dry run”: August 2013}

In preparation for the field experiment, automated procedures for generating and analyzing gravity wave products were tested as part of a larger coordinated DEEPWAVE “dry run" from 5 to 18 August 2013. Immediately after download and postprocessing, AIRS gravity wave products were plotted and then uploaded as image files to an online field catalog, where the science team could access this imagery through a web tool, along with many other products, such as forecasts from a small subset of operational NWP systems. The DEEPWAVE science team convened daily via teleconference to review latest forecast and satellite "nowcast" guidance and then plan hypothetical NGV science flights to observe deep gravity wave dynamics 


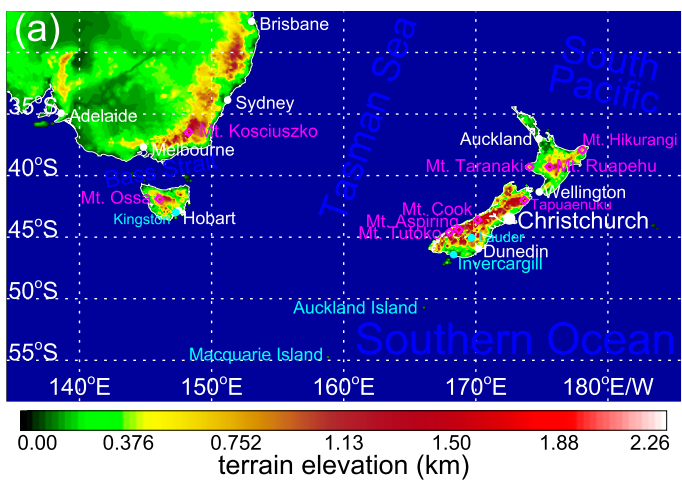

(c) June-July $2003-20113 \mathrm{hPa}$

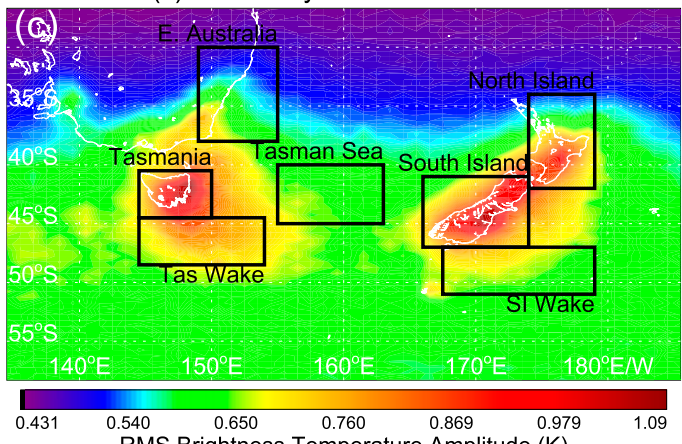

(e) June-July 2003-2011 $80 \mathrm{hPa}$
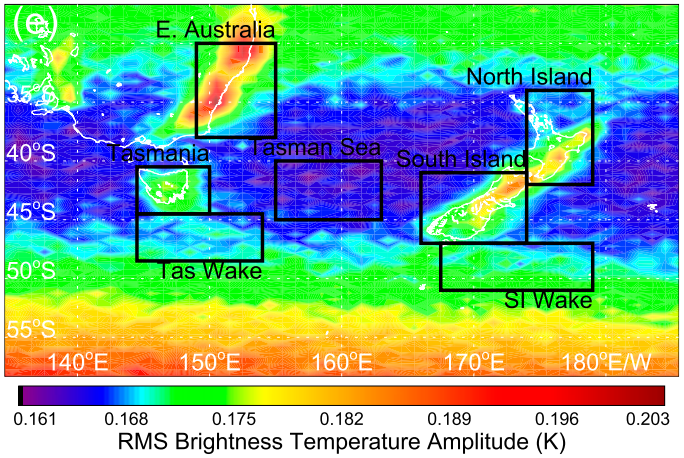

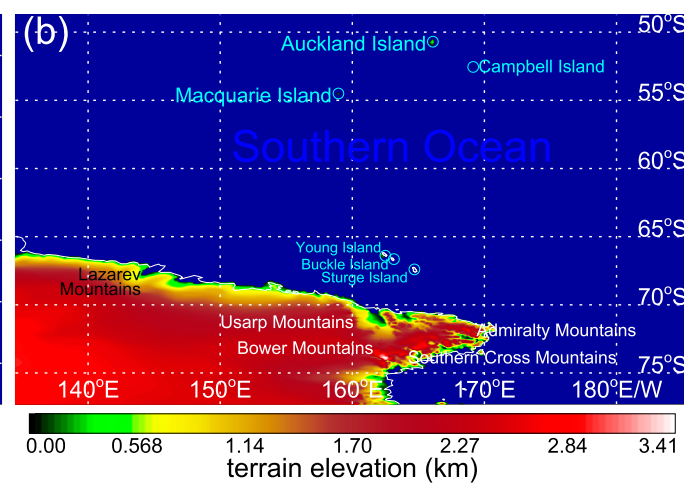

(d) June-July 2003-20113 hPa

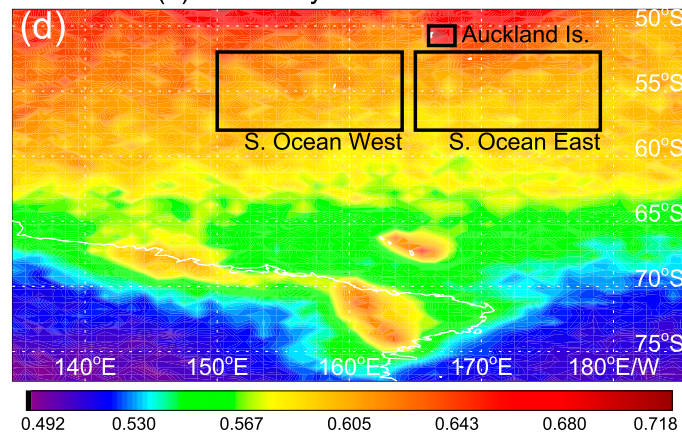

RMS Brightness Temperature Amplitude $(\mathrm{K})$

(f) June-July $2003-201180 \mathrm{hPa}$

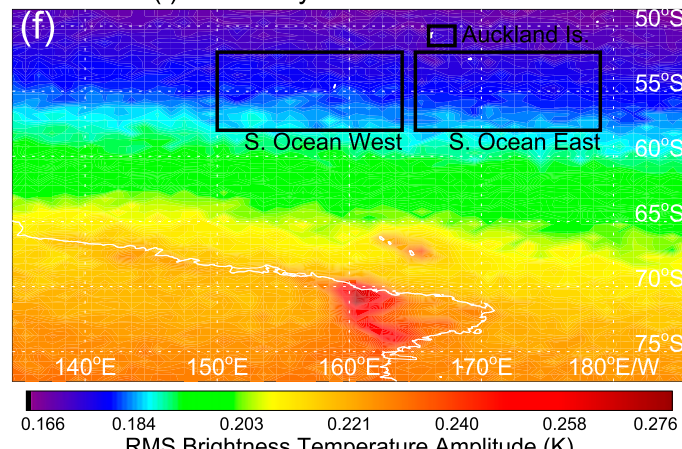

FIG. 4. (a) Northern and (b) southern areas of the greater DEEPWAVE area of operations, showing seas and oceans (blue text), major cities (white text), small observing stations and subantarctic islands (aqua text), and major mountain peaks (purple text, and white text over Antarctica). AIRS $\sigma_{T_{B}}$ at (c),(d) $3 \mathrm{hPa}$ and (e),(f) $80 \mathrm{hPa}$ averaged over June and July for years 2003-11 within $1^{\circ} \times 0.5^{\circ}$ longitude-latitude grid boxes. Based on major climatological variance peaks, black boxes mark zones where times series of $\sigma_{T_{B}}$ were studied for DEEPWAVE science (see Figs. 5, 9, and 14).

addressing specific DEEPWAVE science questions. Since no NGV flights were actually conducted during the dry run, uploaded AIRS NRT and STND gravity wave imagery served as the available "deep" gravity wave observation for objectively assessing the success or failure of NGV flights that were devised and hypothetically executed on previous days.

Figure 6 shows a sample forecast from the Coupled Ocean-Atmosphere Mesoscale Prediction System (COAMPS; Doyle et al. 2011), which provided regional NWP forecasts at $15 \mathrm{~km}$ horizontal resolution out to $+60 \mathrm{~h}$, updated every $6 \mathrm{~h}$, throughout the dry-run period. The red-blue contours show $+36 \mathrm{~h}$ forecasts of divergence $D=\nabla_{h} \cdot \mathbf{U}_{h}$ of the horizontal wind velocity $\mathbf{U}_{h}$ at a midstratospheric level of $2 \mathrm{hPa}$, valid at 1200 UTC 10 August 2013. The $D$ forecasts at lower altitudes (not shown) revealed resolved orographic gravity waves forced by flow across the mountainous terrain of both the South Island of New Zealand and Tasmania. At these higher altitudes, the forecast waves attained a "trailing" structure in which phase lines have rotated horizontally to a southeast-northwest alignment and 
South Island

(a) Asc+Des $2 \mathrm{hPa}$
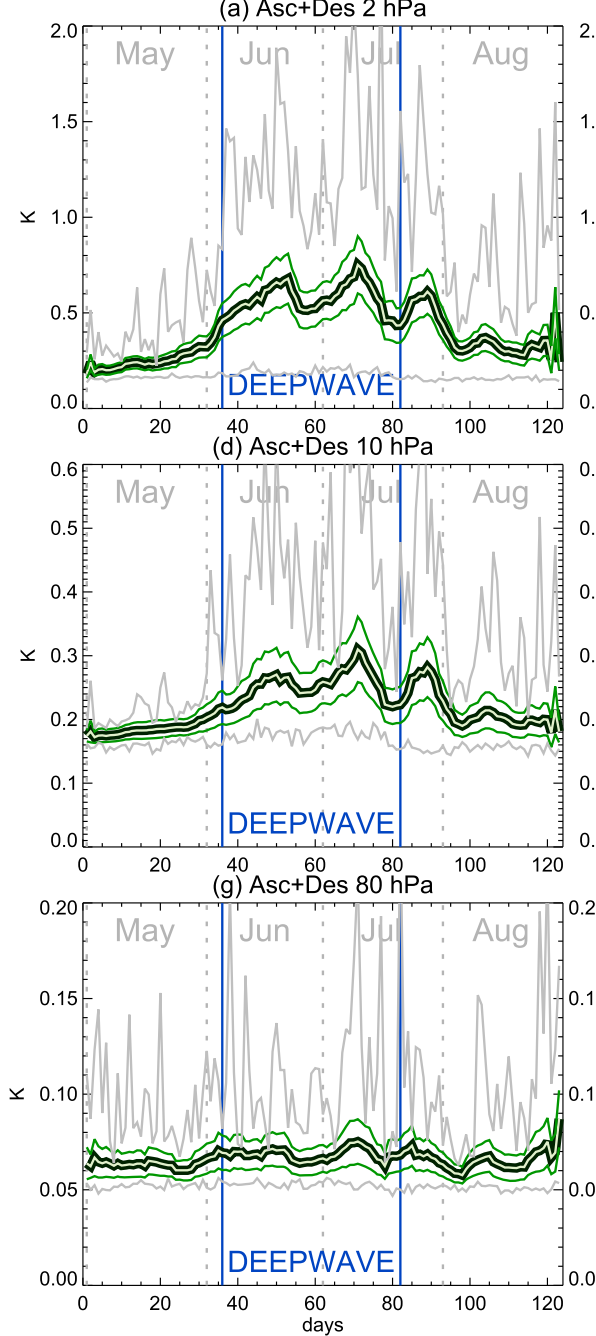

FIG. 5. Time series (days after $30 \mathrm{Apr}$ ) of AIRS $15 \mu \mathrm{m} \sigma_{T_{B},}$, computed from $T_{B_{3}}^{\prime}$ swath imagery after $3 \times 3$ FOV smoothing from May through August for the years 2003-11, within three of the geographic zones identified in Fig. 4: (a)-(c) 2, (d)-(f) 10, and (g)-(i) 80 hPa. Thick black-green curve shows mean, thinner green curves above and below it show plus and minus one standard deviation, and the maximum and minimum values from 2003 to 2011 are shown in gray. The 6 Jun-21 Jul DEEPWAVE NGV period is marked in blue.

wave groups have migrated south and southeast of the parent terrain. Since improved understanding of trailing-wave dynamics was a DEEPWAVE science topic (Fritts et al. 2016; Jiang et al. 2019), a hypothetical NGV flight was devised to sample the atmosphere across and downstream of Tasmania to explore deep trailing orographic gravity waves.

Figure 7 shows that flight track overlaid on the AIRS NRT brightness temperature perturbations acquired on 10 August 2013 from an overpass at 1522 UTC: the adjacent swath to the east occurred $\sim 98.8$ min earlier. The 7 way points labeled on the flight track reveal four sequential transects of Tasmania (way points 1-5) to observe local orographic gravity waves, followed by a transect to the south of Tasmania and a long inbound leg to observe trailing waves from Tasmania as well as any possible nonorographic waves, a total flight distance of just over $\sim 7300 \mathrm{~km}$. Given an NGV cruise speed of $\sim 200 \mathrm{~m} \mathrm{~s}^{-1}$, this yields a flight time close to the NGV's nominal $\sim 10 \mathrm{~h}$ maximum. Since all planned NGV flights for DEEPWAVE were to occur at night due to onboard active and passive optical remote sensors (Fritts et al. 2016), nominal takeoff was at $\sim 0600$ UTC (just after dusk at 1800 LT) with nominal landing in Christchurch at $\sim 1600$ UTC.

With the caveat that most regions near Tasmania were sampled by this flight some hours prior to the AIRS overpass, 100 and $2.5 \mathrm{hPa} T_{B}^{\prime}$ imagery in Fig. 7 show 


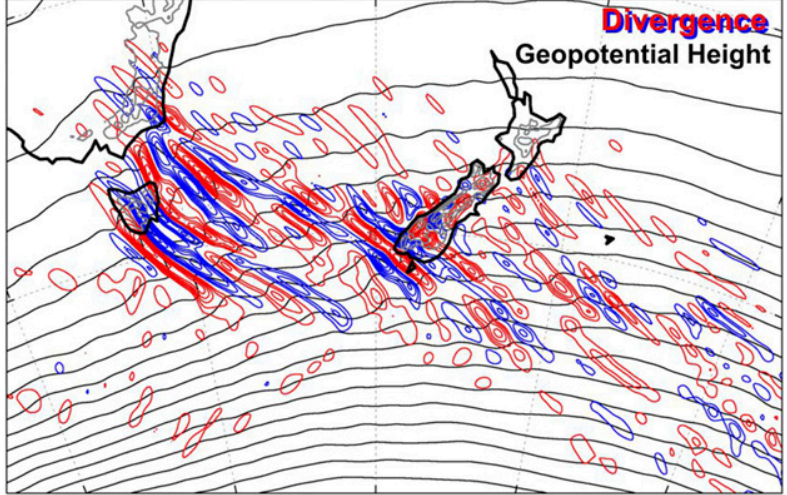

FIG. 6. COAMPS $+36 \mathrm{~h}$ forecasts of $2 \mathrm{hPa}$ geopotential height (black contours, interval $120 \mathrm{~m}$ ) and $2 \mathrm{hPa}$ divergence (red-blue contours, interval $4 \times 10^{-5} \mathrm{~s}^{-1}$ ), valid at 1200 UTC 10 Aug 2013 , from the DEEPWAVE "dry run."

that the 4 flight transects of Tasmania would have observed orographic gravity wave activity throughout the stratosphere. The $2.5 \mathrm{hPa} T_{B}^{\prime}$ imagery in Fig. $7 \mathrm{~b}$ also suggests that flight segments along way points 5-6 and early portions of way points 6-7 would have observed trailing-wave structure in the upper stratosphere.

Figure 6 also reveals strong predicted wave activity to the north of Tasmania associated with trailing gravity waves from the Great Dividing Range in eastern Australia, for which there was little evidence in the AIRS imagery in Fig. 7. Similar forecast features were observed on other days, and raised the following question: Were the forecasts producing some spurious gravity waves? This issue became important to resolve to ensure the NGV was not vectored into regions lacking waves based on spurious gravity waves in a forecast, thereby wasting valuable flight hours and resources.

To investigate this, we first noted that geopotential height contours in Fig. 6 become more separated to the north, revealing a meridional shear in $2 \mathrm{hPa}$ stratospheric wind speeds $U_{h}=\left|\mathbf{U}_{h}\right|$, from $\sim 60$ to $70 \mathrm{~m} \mathrm{~s}^{-1}$ to the southeast of Tasmania to $\sim 30 \mathrm{~m} \mathrm{~s}^{-1}$ near the south coast of Australia. Assuming stationary orographic gravity waves, the vertical wavelength $\lambda_{z}=2 \pi\left|U_{h} \cos (\Delta \varphi)\right| / \bar{N}$, where $\Delta \varphi$ is the difference in azimuth angle between $\mathbf{U}_{\mathbf{h}}$ and the gravity wave horizontal wavenumber vector $\mathbf{K}_{h}$, and $\bar{N}$ is background buoyancy frequency. Given $\bar{N} \sim 0.017 \mathrm{rad} \mathrm{s}^{-1}$ and $\Delta \varphi \sim 30^{\circ}$, this yields $\lambda_{z} \sim 22 \mathrm{~km}$ to the southeast and $\sim 9 \mathrm{~km}$ to the northeast.

Small $\lambda_{z}$ waves yield smaller amplitude $T_{B_{i}}^{\prime}$ oscillations due to greater averaging by the broad AIRS kernel functions in Fig. 2a. Spectral visibility functions $\tilde{\varepsilon}_{j}\left(\lambda_{z}\right)$ in appendix B quantify this amplitude attenuation and, for the $2.5 \mathrm{hPa}$ AIRS channel, yield values of $\sim 0.25$ for $\lambda_{z} \sim 22 \mathrm{~km}$ and $\sim 0.03$ for $\lambda_{z} \sim 9 \mathrm{~km}$ [see also Fig. 4 of Alexander and Barnet (2007)]. Peak $D$ amplitudes to the north of Tasmania in Fig. 6 are $\sim 4 \times 10^{-4} \mathrm{~s}^{-1}$. Using the gravity wave polarization relation

$$
T^{\prime}= \pm\left[\frac{\bar{T} \bar{N}}{g K_{h}}\right] D,
$$

\section{AIRS NRT Radiance Perturbations 10 August 2013}

(a) Descending 1522 UTC $100 \mathrm{hPa}$
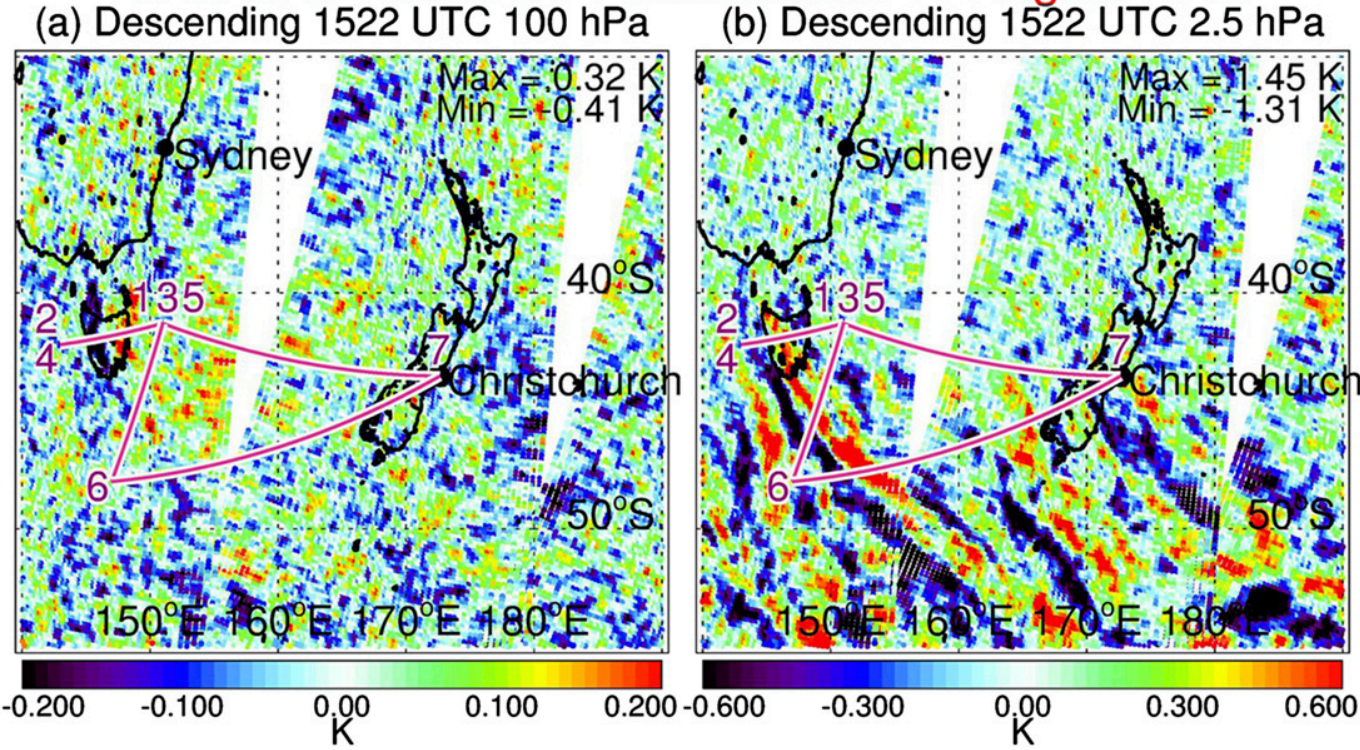

FIG. 7. AIRS NRT brightness temperature perturbations from descending overpasses on 10 Aug 2013 in (a) the $100 \mathrm{hPa}$ and (b) the $2.5 \mathrm{hPa}$ channel. The pink curve shows the hypothetical "dry run" NGV flight track on this day, based on forecast guidance like that shown in Fig. 6, with way points labeled sequentially. 


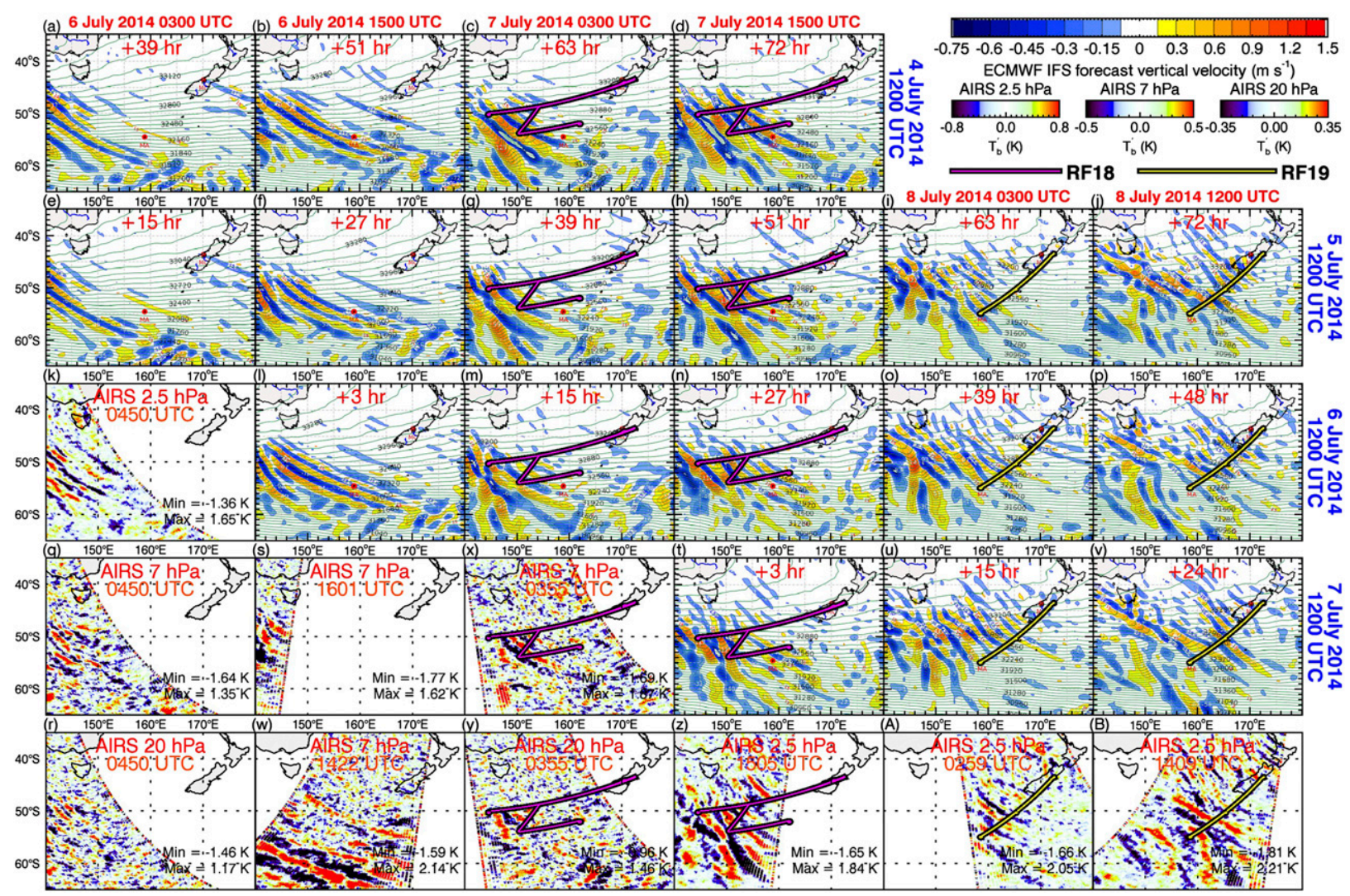

FIG. 8. Top two rows and plots to right on rows 3 and 4 show ECMWF IFS forecasts of vertical velocity (see color bar top right) at $7 \mathrm{hPa}$. Panels are organized by forecast verification date (column: see red text at top) and by forecast initialization time (row: see blue text at far right). Forecast and initialization dates advance in 12 and $24 \mathrm{~h}$ steps, respectively, from left to right and from top to bottom, respectively. Remaining panels to left of rows 3-5 show AIRS STND $T_{B}^{\prime}$ at indicated height and time, designed in each case to validate the forecasts in panels above (see 3 color bars for various channels top right). Black-edged fuchsia and gold curves show NGV flight tracks executed as RF18 and RF19, respectively.

where $K_{h}=\left|\mathbf{K}_{h}\right|$ and $g$ is gravitational acceleration, yields temperature amplitudes $\hat{T} \sim 5 \mathrm{~K}$ using $\lambda_{z} \sim 9$ and $\lambda_{h} \sim 150 \mathrm{~km}$. Multiplying this $\hat{T}$ value by $\tilde{\varepsilon}_{j}\left(\lambda_{z}\right) \sim 0.03$ yields an anticipated $\hat{T}_{B_{j}} \sim 0.125 \mathrm{~K}$, well below the rootmean-square (rms) noise floor variance of $\sim 0.35 \mathrm{~K}$ for individual $15 \mu \mathrm{m}$ channels (Pagano et al. 2003).

Thus the forecast $2 \mathrm{hPa}$ gravity waves to the north of Tasmania in Fig. 6 were likely reliable, but were not observable in Fig. $7 \mathrm{~b}$ because their small vertical wavelengths yielded a perturbation amplitude that was below the noise-detection threshold for this AIRS channel.

\section{In-field flight planning and science}

\section{a. Validating forecasts of deep nonorographic gravity waves}

AIRS NRT imagery played an important unanticipated role in planning NGV flights far to the south and west of Christchurch to observe deep nonorographic gravity waves. As shown in the upper panels of Fig. 8, stratospheric forecasts from high-resolution NWP models employed operationally during DEEPWAVE (see Table 3 of Fritts et al. 2016) often showed explicitly resolved gravity waves over the Southern Ocean far from orographic sources. Since deep nonorographic gravity wave dynamics were a prime science focus of DEEPWAVE, these forecast gravity waves elicited flight-planning interest. However, the reliability of these forecast gravity waves was questioned, given that spurious resolved gravity waves can often appear in NWP model forecasts: well-known examples include spontaneous emission via adjustment to erroneously unbalanced analysis increments within the atmospheric initial conditions provided by data assimilation (Lynch and Huang 2010), and various internal sources of model error affecting prediction of resolved nonorographic gravity waves, such as spurious forcing tendencies from subgridscale parameterizations of deep and shallow convection (e.g., Horinouchi et al. 2003).

Given that baroclinic storms, a likely source of nonorographic gravity waves along the Southern Ocean 
(O'Sullivan and Dunkerton 1995; Hendricks et al. 2014), move west to east, the science team developed a strategy of comparing forecast nonorographic gravity waves to the west of the DEEPWAVE region of airborne operations (RAO) with AIRS NRT gravity wave imagery. This gave the team a few days to validate these upstream forecast waves before tropospheric westerlies brought the source regions into the DEEPWAVE RAO and within flight range of the NGV.

The left columns of Fig. 8 show examples of this upstream forecast validation during DEEPWAVE. Upper panels show operational forecasts of $7 \mathrm{hPa}$ vertical velocity from the European Centre for Medium-Range Weather Forecasts (ECMWF) Integrated Forecasting System (IFS), revealing intense nonorographic gravity waves predicted to the south of Tasmania on 6 July. The AIRS gravity wave imagery acquired on 6 July, shown in the lower-left panels of Fig. 8, validated many aspects of this predicted upstream wave activity, including its geographical location and horizontal phase structure. This NRT validation of the 6 July forecasts allowed the science team to more confidently plan two separate NGV research flights on 7 and 8 July (RF18 and RF19, respectively) to intercept and profile deep nonorographic gravity waves as nonorographic forcing regions over the Southern Ocean evolved and moved eastward into the RAO and within range of the NGV. Executed RF18 and RF19 flight paths (black-fuchsia and black-yellow curves, respectively, in Fig. 8) based on this prevalidated forecast guidance reveal intercepts with intense nonorographic gravity waves imaged by AIRS on 7 and 8 July. Further evidence of the success of this strategy in vectoring the $\mathrm{NGV}$ to observe deep nonorographic gravity waves is provided in section $5 \mathrm{~d}(2)$.

\section{b. "Nowcast" monitoring of gravity wave activity}

Yellow and red curves in Fig. 9 show time series of NRT and STND AIRS $15 \mu \mathrm{m} \sigma_{T_{B}}$ during 2014 within the 4 regions shown in Fig. 9q. As new AIRS observations appeared, these curves were updated for all $15 \mu \mathrm{m}$ channels over all 10 regions shown in Fig. 4 to monitor how regional gravity wave activity was evolving within the DEEPWAVE RAO relative to the 9-yr climatologies shown in green (see Fig. 5). The NRT and STND curves lie on top of one another in all panels of Fig. 9, and were correlated in all regions and all channels at $>0.99$, providing strong in-field validation of our inaugural use of NRT AIRS radiances as our stratospheric gravity wave nowcasting product for DEEPWAVE flight planning and validation and monitoring of wave fields.

The aqua curves in Fig. 9 show the corresponding CrIS $15 \mu \mathrm{m} \sigma_{T_{B}}$ time series. These have generally lower noise floors than the corresponding AIRS results shown in red and yellow, as discussed in section $2 \mathrm{~b}$, and thus also provided very effective nowcast monitoring of gravity wave activity as our operational backup to AIRS NRT radiances during DEEPWAVE.

Prominent outbreaks of deep-propagating gravity wave activity were progressively revealed during the 2014 austral winter by these time series. For example, the South Island time series, shown in the left column of Fig. 9, revealed an unanticipated early outbreak of intense deep wave activity during 20-28 May, a period when ground operations had just commenced, but prior to onset of NGV operations on 6 June. Similar peaks in the South Island wake region identified trailing-wave dynamics at higher altitudes (Fig. 9b). Enhanced wave activity also occurred over Tasmania (Fig. 9c) and its wake region (not shown) at this time. With the onset of NGV operations in Christchurch on 6 June, Fig. 9a reveals two intense deep outbreaks of gravity wave activity in which $2 \mathrm{hPa} \sigma_{T_{B_{j}}}$ peaked well above climatological values. The first outbreak during 14-15 June led to three NGV flights. The first flight on 13 June (RF3) sampled upstream forecast-sensitive areas for anticipated strong forcing across the Southern Alps on the following days, while the remaining two flights on 14 and 16 June (RF4 and RF5) profiled deep orographic and trailing waves. The second outbreak during 19-22 June spurred consecutive flights on 19 and 20 June (RF7 and RF8) to sample deep orographic gravity wave dynamics in and around the South Island. Another smaller peak occurred in Fig. 9a on 1 July during a period of 4 successive NGV flights to study evolving orographic gravity waves (RF11-14; Fritts et al. 2016; Portele et al. 2018), followed by another longer outbreak peaking on 13 July when another dedicated NGV flight (RF22) observed intense deep mountain-wave activity over the South Island (Bossert et al. 2015, 2017).

After NGV operations ended, an extended but weaker gravity wave outbreak peaked on 23 July, after which deep wave activity over the South Island abated and remained quiet throughout August. Intense wave activity occurred at lower altitudes in late July (see Fig. 9m) but did not appear at higher altitudes over the South Island. The dynamics of this unusual event were studied by Ehard et al. (2017), who attributed lack of deep penetration above the South Island to breaking in the lower stratospheric "valve layer" (Kruse et al. 2016).

Figure 9 also shows that, while deep orographic gravity wave activity was more prevalent over the South Island in June than July, nonorographic gravity wave activity over the Southern Ocean West region was fairly weak during mid-late June but picked up during July. These features were reflected in NGV flight plans, with most June research flights focused on deep orographic gravity waves 

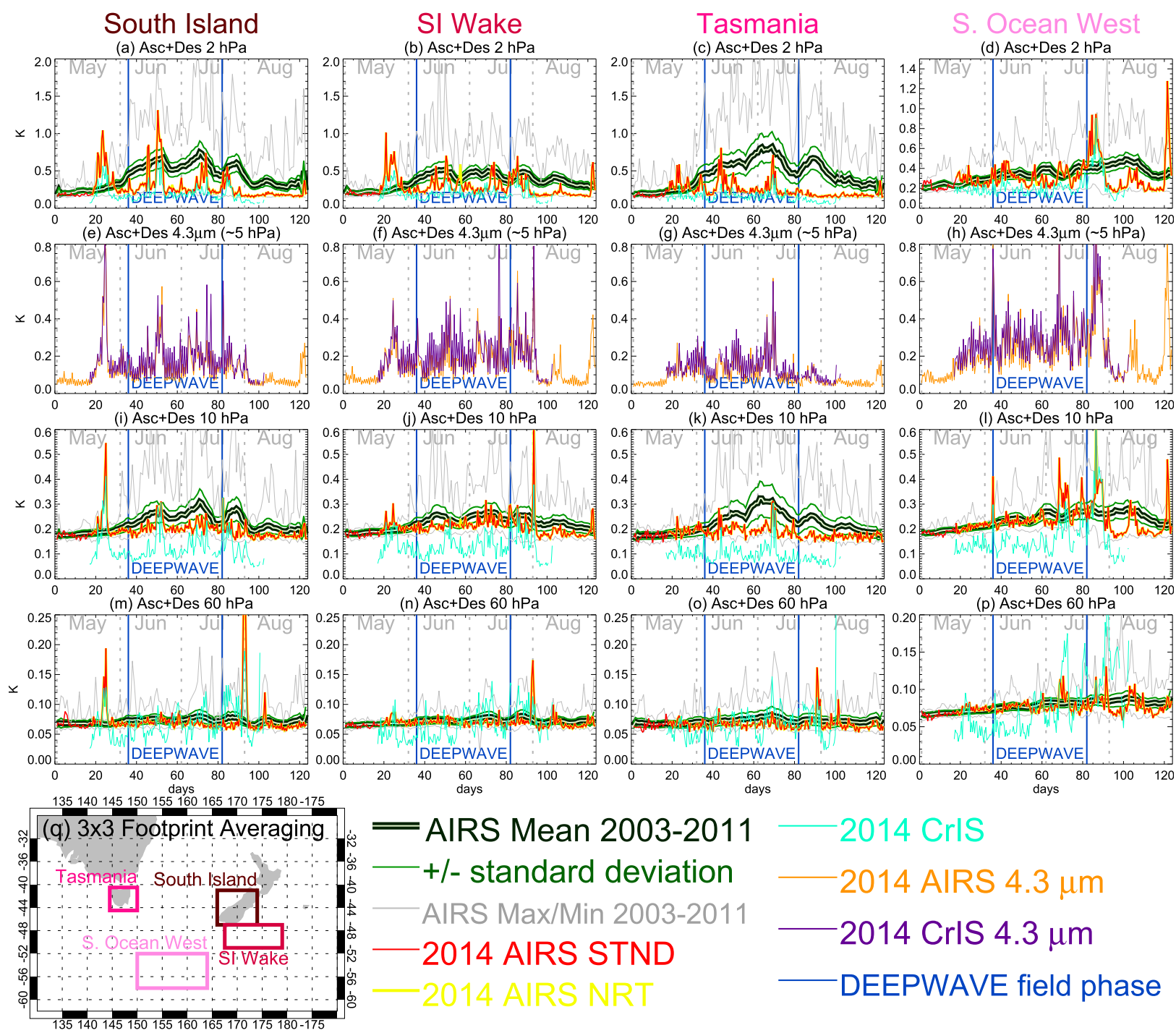

2014 CrIS

2014 AIRS $4.3 \mu \mathrm{m}$

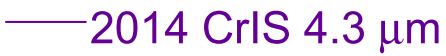

- DEEPWAVE field phase

FIG. 9. Time series (days after $30 \mathrm{Apr}$ ) of $\sigma_{T_{B}}$, computed from $T_{B_{i}}^{\prime}$ swath imagery after $3 \times 3$ FOV smoothing from May through August within 4 of the geographic zones identified in Fig. 4, as shown in panel (q). Green and gray curves show the 9-yr AIRS $15 \mu \mathrm{m}$ climatologies as in Fig. 5. Values from 2014 during DEEPWAVE at $15 \mu \mathrm{m}$ are shown for AIRS NRT (yellow), AIRS STND (red), and CrIS (aqua): (top row) AIRS $2 \mathrm{hPa}$ and CrIS $3 \mathrm{hPa}$, (third row) AIRS and CrIS $10 \mathrm{hPa}$, and (fourth row) AIRS and CrIS $60 \mathrm{hPa}$. (second row) 2014 results only from the $4.3 \mu \mathrm{m}$ radiance channels from AIRS (orange) and CrIS (purple). The 6 Jun-21 Jul DEEPWAVE NGV period is marked in blue. See also color key and plot labels on bottom row.

over the South Island and Tasmania, whereas a series of southern survey flights was conducted during July to observe deep nonorographic gravity waves over the Southern Ocean (Fig. 8 and Table 4 of Fritts et al. 2016). This flight planning is assessed in greater depth in section 5.

\section{Postmission assessments and validation}

\section{a. AIRS gravity wave activity at 15 and $4.3 \mu \mathrm{m}$}

After the 2014 field campaign, an independent analysis of gravity waves in $4.3 \mu \mathrm{m}$ AIRS radiances was presented by Hoffmann et al. (2014, 2016). Gisinger et al. (2017) applied their methods to study deep gravity wave dynamics over the South Island during DEEPWAVE. Their $4.3 \mu \mathrm{m}$ observations and algorithms yielded a mean occurrence frequency of deep orographic gravity wave activity over the South Island for June-July 2014 of $\sim 2 \%$, a value many times lower than any comparable value inferred in previous austral winters (see Fig. 15 of Gisinger et al. 2017). Using our $15 \mu \mathrm{m} \sigma_{T_{B_{j}}}$ time series in Fig. 9a, together with a conservative wave detection threshold of $\sigma_{T_{B_{j}}} \geq 2$ times background noise levels, we derive a corresponding mean occurrence frequency for deep orographic gravity wave activity 
over the South Island during June-July 2014 of $\sim 20 \%$. Thus, this $2 \%$ Gisinger et al. (2017) value is an order of magnitude smaller than our finding of orographic gravity wave occurrence rates based on AIRS $15 \mu \mathrm{m}$ radiances, and also many times less than orographic gravity wave occurrence rates derived from ground-based and NGV observations over the South Island during DEEPWAVE (e.g., Kaifler et al. 2015; Fritts et al. 2016; Smith et al. 2016; Kruse et al. 2016; Jiang et al. 2019; Pautet et al. 2019). Since this Gisinger et al. (2017) result implies that there were almost no deep orographic gravity waves to observe throughout DEEPWAVE from AIRS at $4.3 \mu \mathrm{m}$, in contrast to all other DEEPWAVE observations including our $15 \mu \mathrm{m}$ AIRS products, here we look deeper into their results to identify possible sources of these large unexplained discrepancies.

Close inspection of Fig. 9 shows that $4.3 \mu \mathrm{m} \sigma_{T_{B_{i}}}$ time series (second row) have a "noisier" appearance than the $15 \mu \mathrm{m}$ time series. This arises due to a diurnal oscillation caused by systematic differences in $4.3 \mu \mathrm{m} \sigma_{T_{B}}$ between daytime (ascending) and nighttime (descending) overpasses.

To investigate further, Figs. 10a and $10 \mathrm{~b}$ show mean AIRS brightness temperatures $\bar{T}_{B_{j}}$ and rms perturbation amplitudes $\sigma_{T_{B}}$, respectively, averaged throughout June-July 2014 over a broad DEEPWAVE region, with means separated into ascending (daytime) and descending (nighttime) overpasses, for both 15 and $4.3 \mu \mathrm{m}$ channels. Since diurnal tidal amplitudes are weak, stratospheric temperatures vary only weakly between night and day. This is borne out by $\bar{T}_{B_{j}}$ for the $15 \mu \mathrm{m}$ channels in Fig. 10a, which reveal little if any day-night asymmetry. By contrast, $\bar{T}_{B_{j}}$ at $4.3 \mu \mathrm{m}$ is $\sim 10 \mathrm{~K}$ larger on ascending (daytime) overpasses relative to descending (nighttime) overpasses. Since stratospheric temperatures do not change, this implies large changes in $4.3 \mu \mathrm{m}$ RT between day and night. While well-known theoretically (López-Puertas and Taylor 1989; DeSouza-Machado et al. 2007), the specific implication of this result here is that there are major accompanying changes in vertical temperature kernel functions at $4.3 \mu \mathrm{m}$ between day and night that will change not just $\bar{T}_{B_{i}}$, but must also change the visibility of these $4.3 \mu \mathrm{m}$ channels to gravity wave structure between daytime and nighttime overpasses. Consistent with this hypothesis, Fig. 10b also reveals mean gravity wave perturbation amplitudes $\sigma_{T_{B_{j}}}$ at $4.3 \mu \mathrm{m}$ that are nearly a factor of 2 larger when observed at night than during the day: again, no corresponding day-night asymmetries are evident in $\sigma_{T_{B_{j}}}$ in any $15 \mu \mathrm{m}$ channel.

To investigate this finding theoretically, we performed non-LTE CRTM calculations (e.g., Chen et al. 2013; Yin 2016) to derive temperature kernel functions for all AIRS 15 and $4.3 \mu \mathrm{m}$ channels at a range of different solar
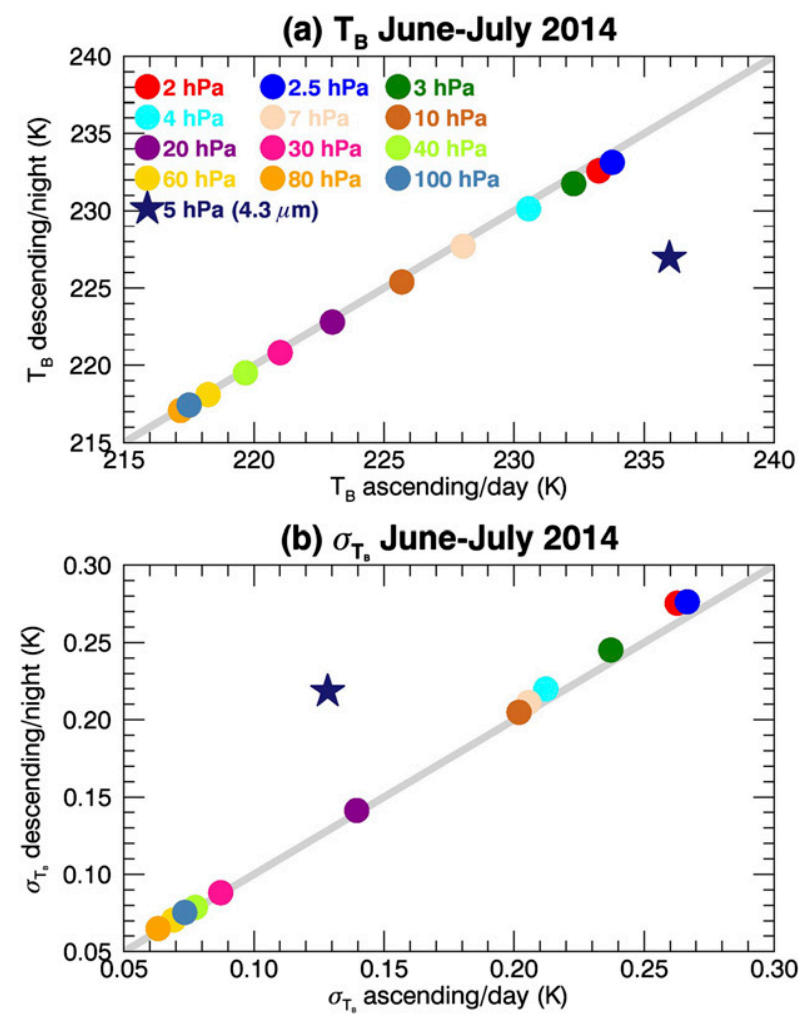

FIG. 10. (a) Mean brightness temperatures $\bar{T}_{B_{j}}$ and (b) rms perturbation brightness temperatures $\sigma_{T_{B_{j}}}$ for indicated AIRS channels $j$, separated according to daytime (ascending) and nighttime (descending) observations. Means were computed for June-July 2014 over the DEEPWAVE region from $135^{\circ}$ to $185^{\circ} \mathrm{E}$ and $25^{\circ}$ to $55^{\circ} \mathrm{S}$. All $\sigma_{T_{B_{j}}}$ values were computed after $3 \times 3 \mathrm{FOV}$ smoothing of $T_{B_{j}}^{\prime}$ swath imagery.

zenith angles $\chi$. Background temperature and constituent profiles were kept fixed in all cases. Figure 11a shows results for a representative $15 \mu \mathrm{m}$ channel, revealing no variations between day and night, consistent with the observations in Fig. 10. By contrast, results for a representative $4.3 \mu \mathrm{m}$ channel in Fig. 11b show large changes as $\chi$ changes, with the nighttime temperature kernel functions $\mathscr{K}_{i}(z)$ about a factor of 2 larger than daytime values. Daytime kernels also extend higher into the atmosphere due to solar excitation of additional $\mathrm{CO}_{2}$ band transitions that do not occur at night (López-Puertas and Taylor 1989). Theoretical $\bar{T}_{B_{j}}$ are computed for each $\chi$ and reveal values in close agreement with observed values in Fig. 10a: in particular, they reproduce the observed $10 \mathrm{~K} \bar{T}_{B_{j}}$ difference between day and night at $4.3 \mu \mathrm{m}$. Corresponding gravity wave visibility functions in Fig. 11c reveal factor-of-2 increases in sensitivity to gravity waves at night relative to day for all gravity wave $\lambda_{z}$, in excellent quantitative agreement with the observed factor-of-2 differences in $4.3 \mu \mathrm{m} \sigma_{T_{B_{j}}}$ observed between night and day in Fig. 10b. 
(a) Ch $74\left(667.53 \mathrm{~cm}^{-1}\right)$

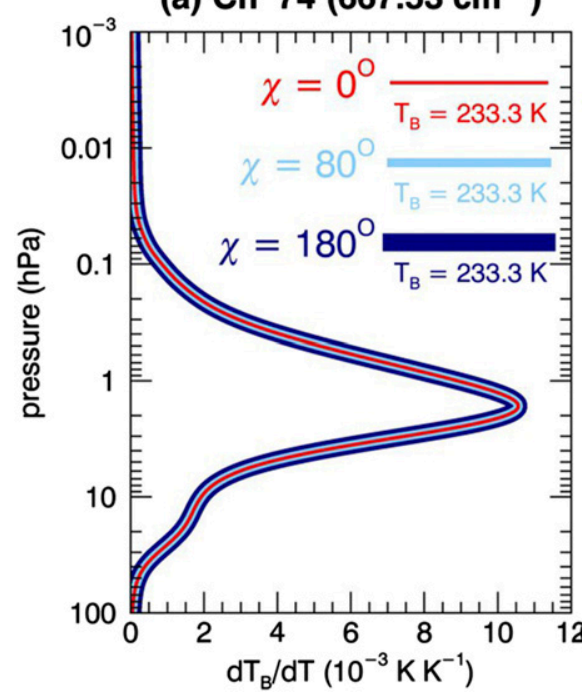

(b) Ch $2049\left(2330.97 \mathrm{~cm}^{-1}\right)$

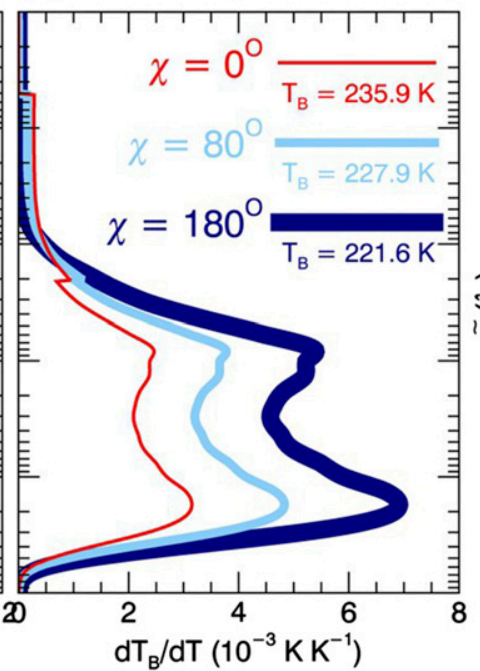

(c) Spectral Visibility Ch 2049

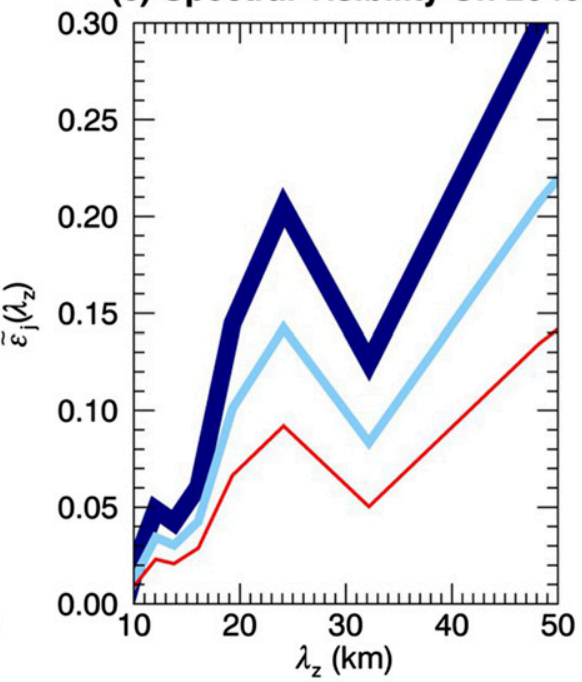

FIG. 11. AIRS kernel functions $\mathscr{T}_{i}(z)$ computed for the indicated (a) $15 \mu \mathrm{m}$ channel and (b) $4.3 \mu \mathrm{m}$ channel. Results are shown for different local solar zenith angles $\chi: 0^{\circ}$ (red curves, sun overhead), $80^{\circ}$ (aqua curve, sun low on horizon), and $180^{\circ}$ (navy curves, nighttime). Calculations use same backgrounds and vertical resolution in each case (see appendix A). Mean brightness temperatures resulting from these RT calculations are listed in each panel. (c) Gravity wave visibility functions $\tilde{\varepsilon}_{j}\left(\lambda_{z}\right)$ derived from the $4.3 \mu \mathrm{m}$ kernel functions in (b), using relations in appendix B. For easier quantitative intercomparison, all curves in (c) are normalized by $\tilde{\varepsilon}_{j}(0)$ for the nighttime profile.

Systematic day-night differences in AIRS $4.3 \mu \mathrm{m} \sigma_{T_{B_{i}}}$ have been documented previously by Hoffmann et al. (2013), and subsequently by Hoffmann et al. (2014) in both AIRS and the Infrared Atmospheric Sounding Interferometer (IASI) on the European MetOp satellites. Expressing $\sigma_{T_{B_{j}}}^{2}$ as a sum $\sigma_{\mathrm{gw}}^{2}+\sigma_{\text {noise }}^{2}$ of a gravity wave and detector-noise component, respectively, Hoffmann et al. (2014) ascribed these RT-induced differences entirely to day-night differences in detector noise. By subtracting an inferred day and night $\sigma_{\text {noise }}^{2}$ from $\sigma_{T_{B_{B}}}^{2}$, they argued that day-night RT-induced asymmetries were entirely removed from $\sigma_{\mathrm{gw}}^{2}$. In contrast to their hypothesis, Fig. 11 clearly shows that day-night changes in $4.3 \mu \mathrm{m}$ RT affect the gravity wave detection directly, and therefore cannot be factored out using detector-noise correction procedures.

Since the Hoffmann et al. (2014) algorithms applied by Gisinger et al. (2017) incorrectly ascribe this day-night variance asymmetry entirely to detector noise, then seek to both quantify and remove detector noise based on these assumptions, their algorithms may be removing most of the gravity wave signal as noise, leaving them with little remaining wave activity to observe, potentially explaining their anomalously low wave occurrence rate of $2 \%$. Of course other aspects of their algorithms may also contribute: for now, our work identifies one major weakness in these algorithms, which do not account explicitly for day-night asymmetries in $4.3 \mu \mathrm{m} \mathrm{RT}$, the dominant process controlling gravity wave-induced radiance perturbations within this band. This is sufficient to identify the $2 \%$ occurrence rate of Gisinger et al. (2017) as an observational outlier and plausible origins of this anomalously low value.

This postmission finding of spurious (and previously unrecognized) diurnal variations in gravity wave activity inferred from $4.3 \mu \mathrm{m} \sigma_{T_{B_{j}}}$ validates our original decision to focus on $15 \mu \mathrm{m}$ radiances as our gravity wave nowcast product for DEEPWAVE, as outlined in section 2a. For example, the large diurnal variations in gravity waveinduced $\sigma_{T_{B_{j}}}$ identified in Fig. 10b, due to previously unrecognized aspects of $4.3 \mu \mathrm{m}$ RT directly relevant to gravity wave detection in this band (Fig. 11), could have led to erroneous conclusions about strong diurnal variations in deep orographic wave activity, given plausible dynamical pathways for solar-driven changes in daytime boundary layer processes to modulate surface orographic gravity wave forcing diurnally (e.g., Jiang and Doyle 2008), which may in turn have misinformed flight-planning strategies.

\section{b. Was the South Island a hot spot for deep orographic gravity waves during DEEPWAVE?}

Their $4.3 \mu \mathrm{m}$ results led Gisinger et al. (2017) to question whether the South Island was a hot spot of deep orographic gravity wave activity during DEEPWAVE. Given the results in Figs. 10 and 11, we reassess that conclusion here using observations at both 15 and $4.3 \mu \mathrm{m}$. 
(a) AIRS $2 \mathrm{hPa}(15 \mu \mathrm{m})$

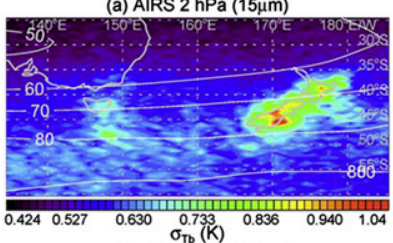

(e) CrIS $3 \mathrm{hPa}(15 \mu \mathrm{m})$

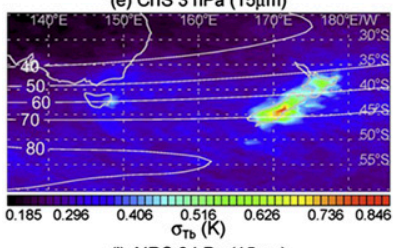

(i) AIRS $2 \mathrm{hPa}(15 \mu \mathrm{m})$

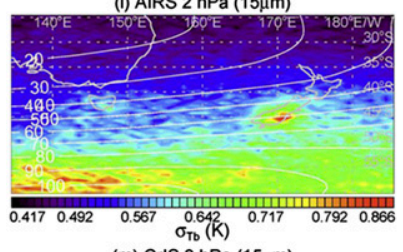

(m) CrIS $3 \mathrm{hPa}(15 \mu \mathrm{m})$

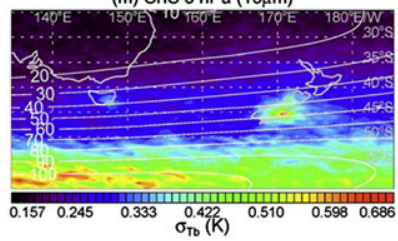

(b) AIRS $7 \mathrm{hPa}(15 \mu \mathrm{m})$ AIRS June 2014 (c) AIRS $80 \mathrm{hPa}(15 \mu \mathrm{m})$

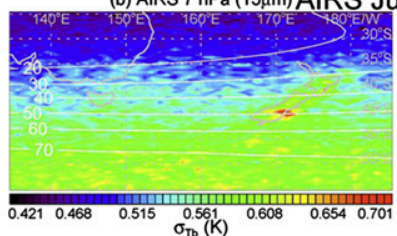

(f) CrIS $10 \mathrm{hPa}(15 \mu \mathrm{m}) \mathrm{CrIS} J$

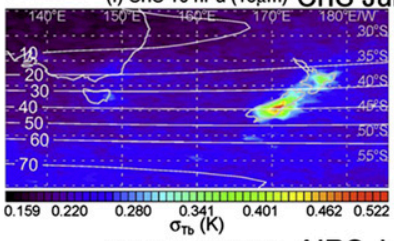

(j) AIRS $7 \mathrm{hPa}(15 \mu \mathrm{m})$ AIRS

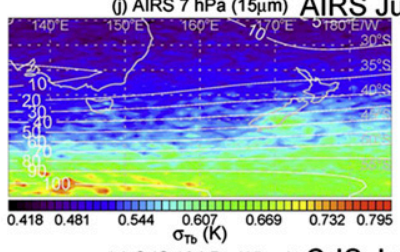

(n) CrIS $10 \mathrm{hPa}(15 \mu \mathrm{m}) \mathrm{CrIS} \mathrm{Ju}$

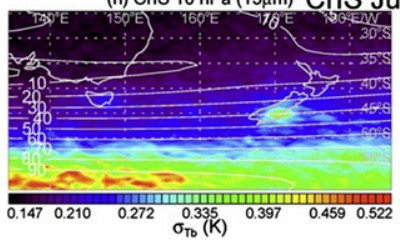

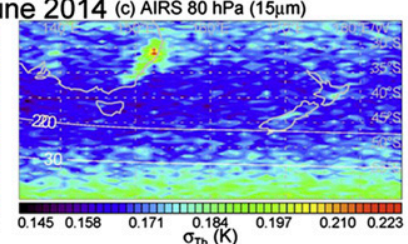

2014 (g) CrIS $80 \mathrm{hPa}(15 \mu \mathrm{m})$
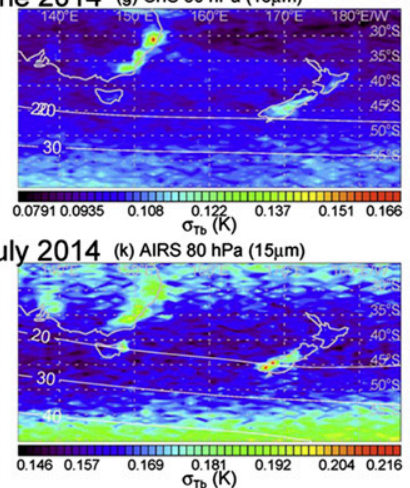

ly 2014 (o) CrIS $80 \mathrm{hPa}(15 \mu \mathrm{m})$

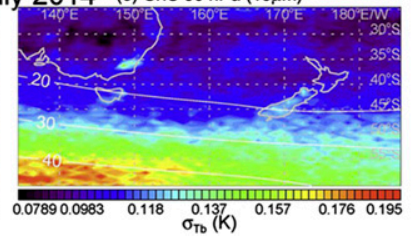

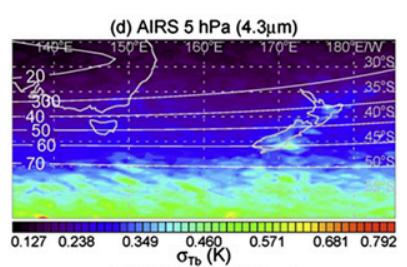

(h) CrIS $5 \mathrm{hPa}(4.3 \mu \mathrm{m})$

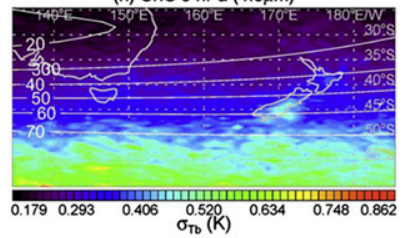

(I) AIRS $5 \mathrm{hPa}(4.3 \mu \mathrm{m})$

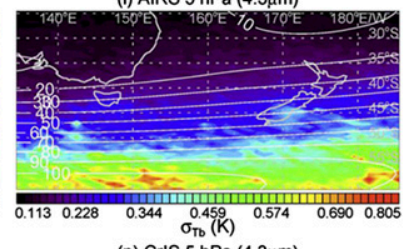

(p) CrIS $5 \mathrm{hPa}(4.3 \mu \mathrm{m})$

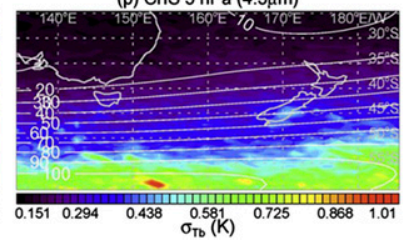

FIG. 12. Color shading in each panel depicts monthly mean $\sigma_{T_{B_{j}}}(\mathrm{~K})$ evaluated over DEEPWAVE RAO within $1^{\circ} \times 0.5^{\circ}$ longitudelatitude bins for the indicated sensor (AIRS or CrIS) and pressure level (hPa) (see Tables A1 and A2). Note different $\sigma_{T_{B_{j}}}$ minima and maxima on color bars beneath each panel. Contours show corresponding monthly mean reanalyzed horizontal wind speeds ( $\mathrm{m} \mathrm{s}^{-1}$ ) at this nominal pressure level (Eckermann et al. 2018). (top row) Monthly mean AIRS values in June 2014 for separate $15 \mu \mathrm{m}$ radiance scenes peaking at (a) 2 , (b) 7, and (c) $80 \mathrm{hPa}$, and for (d) $4.3 \mu \mathrm{m}$ radiances peaking at $\sim 5 \mathrm{hPa}$. (second row) Monthly mean CrIS values in June 2014 for $15 \mu \mathrm{m}$ radiance scenes peaking at (e) 3, (f) 10, and (g) $80 \mathrm{hPa}$, and for (h) $4.3 \mu \mathrm{m}$ radiances peaking at $\sim 5 \mathrm{hPa}$. (third and fourth rows) Corresponding results for AIRS and CrIS, respectively, in July 2014.

Figure 12 shows $\sigma_{T_{B}}$ maps during 2014 in the DEEPWAVE RAO, separating AIRS and CrIS data into June and July means. The first three columns show $15 \mu \mathrm{m}$ results at 2,7 , and $80 \mathrm{hPa}$. White contours show mean wind speeds at each level from the DEEPWAVE atmospheric reanalysis of Eckermann et al. (2018). All $15 \mu \mathrm{m}$ channels show a clear orographic hot spot enhancement over the South Island, apart from the $80 \mathrm{hPa}$ AIRS data in Fig. 12c. This finding is consistent with the orographic gravity wave hot spot enhancement over the South Island observed from the NGV during DEEPWAVE (e.g., Pautet et al. 2019). By contrast, $4.3 \mu \mathrm{m} \sigma_{T_{B_{j}}}$ in the right column of Fig. 12 show much weaker maxima over a smaller fraction of the South Island, superficially consistent with the findings of Gisinger et al. (2017). Especially in June, $\sigma_{T_{B_{j}}}$ at $4.3 \mu \mathrm{m}$ is larger at polar latitudes relative to midlatitudes and to the $15 \mu \mathrm{m}$ maps to the left.

There are two main reasons for these differences. First, stronger mean winds at high latitudes refract waves to larger $\lambda_{z}$, making high-latitude waves more detectable using the deeper $4.3 \mu \mathrm{m}$ kernel functions relative to midlatitude waves (see appendix B; see also Gisinger et al.2017). Second, high-latitude overpasses all occur in polar night where, according to Figs. $10 \mathrm{~b}$ and 11c, $4.3 \mu \mathrm{m} \sigma_{T_{B_{j}}}$ responses are enhanced relative to daytime detections. By contrast, $50 \%$ of South Island observations occur as daytime ascending overpasses, when solar-perturbed RT leads to significantly diminished $4.3 \mu \mathrm{m} \sigma_{T_{B_{i}}}$ responses to gravity waves (Figs. $10 \mathrm{~b}$ and $11 \mathrm{c}$ ). Thus the lack of hotspot activity over the South Island inferred by Gisinger et al. (2017) can result at least in part from complications in $4.3 \mu \mathrm{m}$ RT in quantifying deep wave activity over midlatitude DEEPWAVE sites.

Figure 13 shows monthly mean variations in $15 \mu \mathrm{m}$ $\sigma_{T_{B_{j}}}$ from 2003 to 2011 and in 2014. In contrast to the Gisinger et al. (2017) $4.3 \mu \mathrm{m}$ results, Fig. 13a shows that in 2014, $\sigma_{T_{B_{j}}}$ values over the South Island in both June and July were not record-low outliers at any altitude: for example, June activity during 2009-11 was lower than in 2014. During July, $\sigma_{T_{B}}$ in Fig. $13 \mathrm{~b}$ was noticeably lower but still exceeds 2010 levels. 

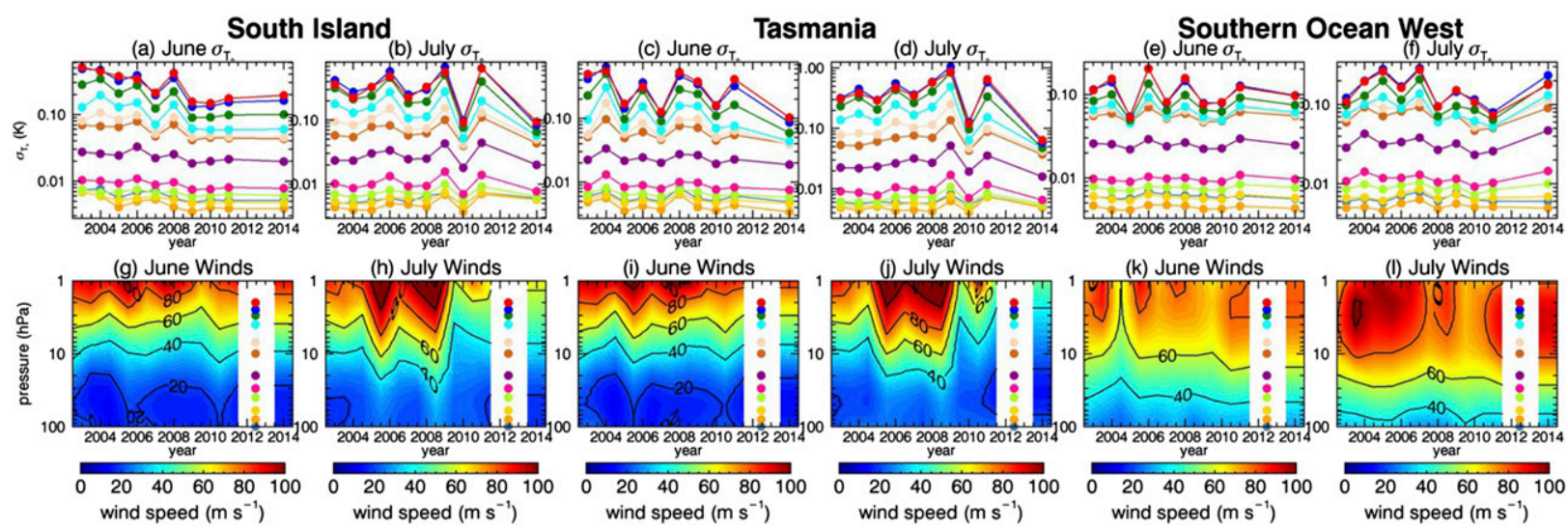

FIG. 13. (top) Monthly mean $\sigma_{T_{B_{B}}}(\mathrm{~K})$ from AIRS $15 \mu \mathrm{m}$ radiances in Table A1 for the years 2003-11 and 2014, shown separately for June and July over the South Island, Tasmania, and Southern Ocean west. Different colored circles correspond to different AIRS channel altitudes as shown in the bottom panels (see also Fig. 10a). (bottom) Contours of monthly mean MERRA2 horizontal winds (m s ${ }^{-1}$ ) vs year.

The more general conclusion to emerge from these comparisons is that year-to-year variations in $\sigma_{T_{B_{j}}}$-based metrics are not accurate proxies for year-to-year variations in intrinsic wave activity. Lower panels of Fig. 13 show wind speeds over each site from the Modern-Era Retrospective Analysis for Research and Applications, version 2 (MERRA2; Gelaro et al. 2017). The $\sigma_{T_{B_{j}}}$ time series at each height correlate strongly with these wind speeds, due again to the way strong (weak) winds refract waves to larger (smaller) $\lambda_{z}$ and produce larger (smaller) $\sigma_{T_{B_{j}}}$ responses, as outlined in appendix B. For example, the smaller $\sigma_{T_{B_{j}}}$ over the South Island in July 2014 arose due to quasi-stationary Rossby-wave activity that split the stratopause jet over the DEEPWAVE RAO and reduced stratopause wind speeds over New Zealand (Gisinger et al. 2017; Eckermann et al. 2018). Yet strong deep orographic gravity wave activity was still frequently predicted and measured from the NGV and groundbased instrumentation over the South Island at various times throughout July 2014 (Bossert et al. 2015, 2017; Bramberger et al. 2017): the weaker background winds refracted these deep orographic gravity waves to smaller $\lambda_{z}$, leading in turn to the smaller observed AIRS $\sigma_{T_{B_{j}}}$ signatures of these waves. Further evidence of this is presented in section $5 \mathrm{~d}(1)$.

\section{c. Deep wave activity over other geographic regions}

While wave activity over the South Island was episodically enhanced during DEEPWAVE, Figs. 12, 13c, and $13 \mathrm{~d}$ show that deep orographic gravity wave activity over Tasmania was unusually suppressed, particularly in July, relative to the climatologies in Fig. 4. By contrast, Fig. 12 shows that deep nonorographic gravity wave activity over the Southern Ocean was notably larger during July, with Fig. $13 \mathrm{f}$ suggesting it reached near record levels relative to previous observation years. These features were reflected in DEEPWAVE NGV flight planning. Only 2 of the 26 NGV flights, both in early-mid-June, were devoted to sampling orographic gravity waves in and around Tasmania, while all southern survey flights to study deep nonorographic gravity waves over the Southern Ocean occurred in July [see Table 4 of Fritts et al. 2016, and section 5d(2)].

Figure 14 illustrates the strong response of $15 \mu \mathrm{m} \sigma_{T_{B_{j}}}$ to wind speeds over all DEEPWAVE regions. Figure $14 \mathrm{~d}$, for example, shows how suppression of $\sigma_{T_{B_{j}}}$ over Tasmania during July and August was associated with weaker stratospheric wind speeds relative to May and June. Likewise, Fig. 14e shows how the rapid increase in nonorographic gravity wave activity over the Southern Ocean in July and August relative to June was associated with both strengthening and descent of peak stratospheric winds. Note also that bursts of deep wave activity over most sites were associated with stratospheric wind intensification over deep layers, while deep attenuation of $\sigma_{T_{B_{j}}}$ during August over Australia and New Zealand was associated with weaker winds at all levels.

\section{d. Flight planning assessment}

\section{1) ORographic GRAVITY WAVES OVER THE SOUTH ISLAND}

Figure 15 plots $T_{B_{i}}^{\prime}$ from AIRS $15-\mu \mathrm{m}$ channels on days when deep orographic gravity wave activity was observed over the South Island (Kaifler et al. 2015; Fritts et al. 2016; Smith et al. 2016; Kruse et al. 2016), For June-July events, the NGV flight path is shown in pink. Maps for 14 June (Fig. 15d), 19-20 June (Fig. 15g,j), and 13 July (Fig. 15v) reveal NGV underflights of wave fields imaged by AIRS. On 25 and 29 June, wave activity 

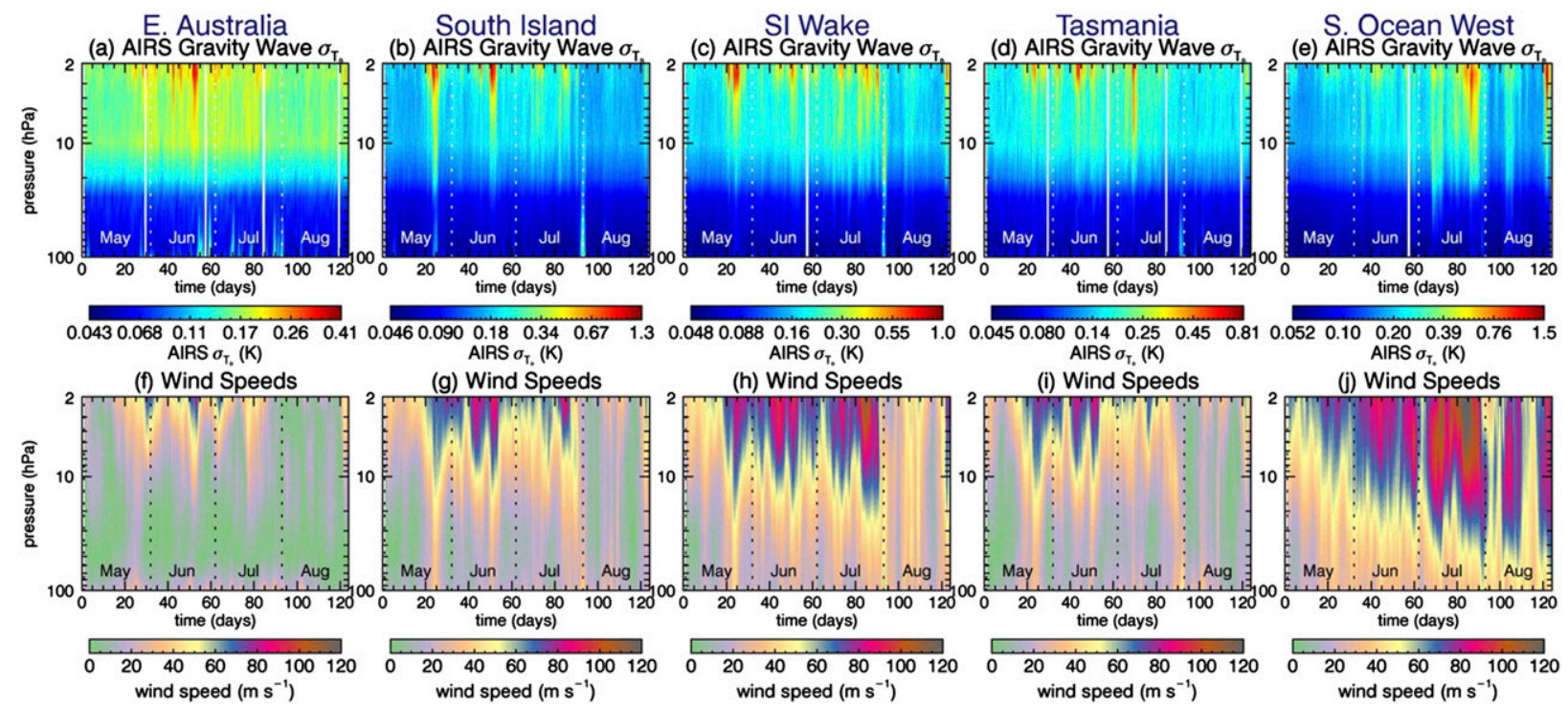

FIG. 14. Time-height cross sections of (top) AIRS $15 \mu \mathrm{m} \sigma_{T_{B}}$ and (bottom) NAVGEM analyzed horizontal wind speeds (Eckermann et al. 2018), each computed within specific regions shown and labeled in Fig. 4: (a),(f) eastern Australia, (b),(g) South Island, (c),(h) South Island wake region, (d),(i) Tasmania, and (e),(j) Southern Ocean west. Heights are shown in log-pressure (hPa) on $y$ axis, which for different AIRS channels $j$ are chosen according to the nominal kernel peak altitude listed in columns 1 and 2 of Table A1. Times are days after 30 Apr 2014, with months marked at their central time and separated by dotted lines.

in upper-level AIRS channels is weak whereas loweraltitude channels reveal gravity waves along the flight track (Figs. 15o,r). AIRS maps for the 4 July event in Figs. $15 \mathrm{~s}-\mathrm{u}$ show little evidence of orographic gravity waves. To understand the origins of these different AIRS responses, Fig. 16 plots horizontal wind profiles over the South Island for all 8 events in Fig. 15. From 25 June to 4 July, when AIRS responses were weakest, stratospheric
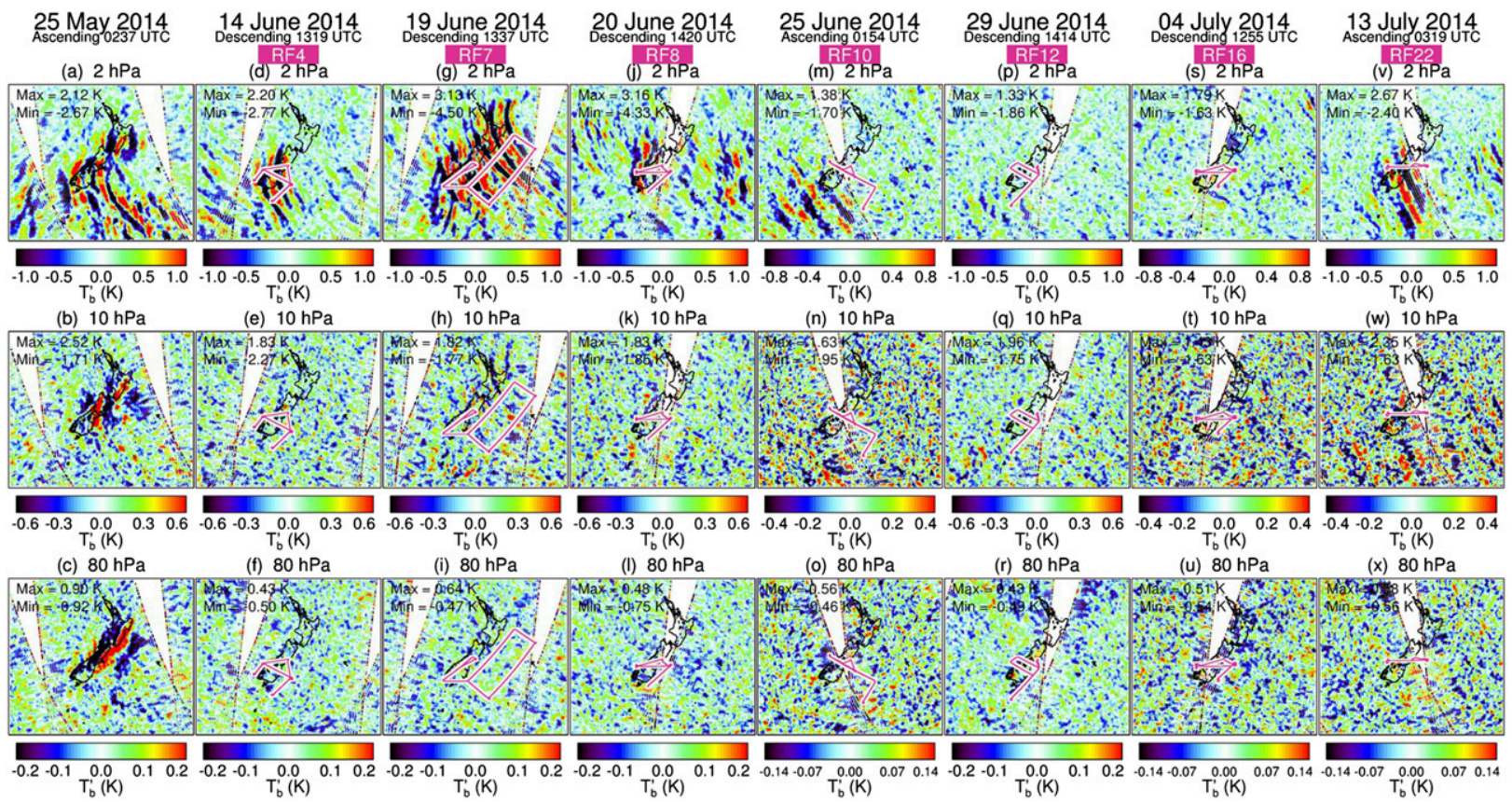

FIG. 15. (from left to right) Time sequence of major deep orographic gravity wave outbreaks over the South Island as imaged by AIRS in its (top) $2 \mathrm{hPa}$, (middle) $10 \mathrm{hPa}$, and (bottom) $80 \mathrm{hPa} T_{B_{j}}$ swath imagery. Overpass times are with respect to Christchurch. Pink-white curves and headings show the NGV research flight on this day. 


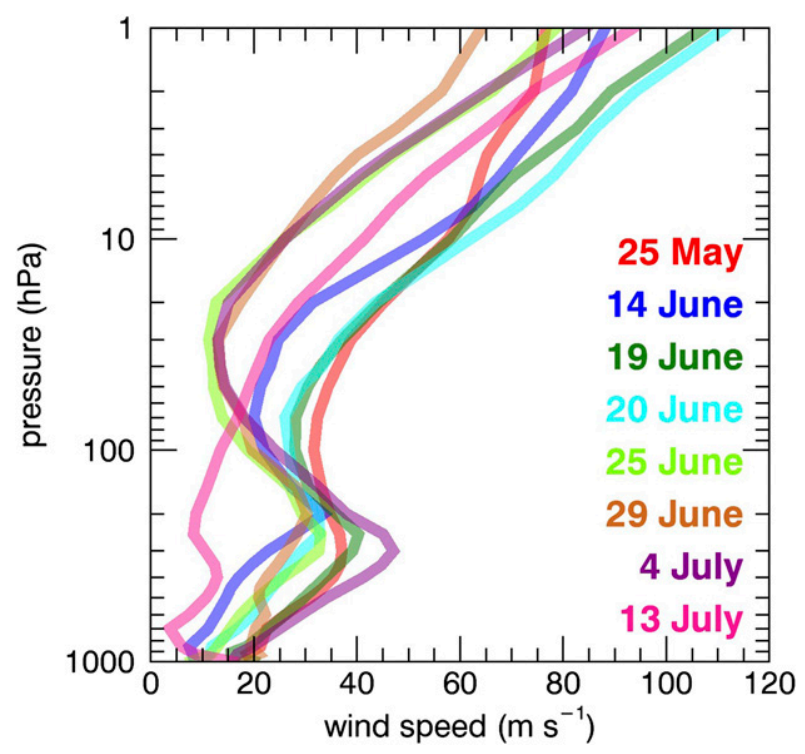

FIG. 16. Vertical profiles of horizontal wind speeds from the DEEPWAVE reanalysis of Eckermann et al. (2018), averaged over the South Island region in Fig. 4 from 0600 to 1500 UTC (corresponding to typical NGV flight times) for the orographic gravity wave events identified in Fig. 15.

winds above $100 \mathrm{hPa}$ were much weaker relative to other days. The resulting contraction of $\lambda_{z}$ in response to these weaker winds again provides a straightforward explanation of the relative lack of visibility of these particular wave events to AIRS.

The lack of AIRS wave signals on 4 July is particularly interesting, given that the NGV measured orographic gravity waves over the South Island on this day with the largest flight-level zonal momentum fluxes of the entire mission (Smith et al. 2016), while ground-based and NGV lidars observed gravity wave perturbations throughout the stratosphere over the South Island with temperature amplitudes of $\sim 5-10 \mathrm{~K}$ (Bramberger et al. 2017). While Bramberger et al. (2017) argued that the 4 July wind minimum at $\sim 50-20 \mathrm{hPa}$ in Fig. 16 led to some wave breaking, their analysis of lidar data suggested that wave activity still penetrated deep into the stratosphere. Increasing wind speeds at upper stratospheric levels during 4 July in Fig. 16 suggest that deep wave activity could potentially be imaged in high-altitude radiances. While the $2 \mathrm{hPa}$ AIRS imagery in Fig. 15s shows weak evidence of possible trailing wave structure near the southern tip of the South Island, the observations are limited by apparent $\hat{T}_{B_{j}}$ amplitudes near noise levels, and that the South Island lies between the edges of two adjacent swaths from separate overpasses.

Given superior noise characteristics of CrIS $15 \mu \mathrm{m} T_{B_{j}}^{\prime}$ that emerged from comparisons in Fig. 9, Fig. 17 shows $T_{B_{j}}^{\prime}$ from $15 \mu \mathrm{m}$ CrIS 3 and $10 \mathrm{hPa}$ channels on 4 July.
In this overpass the South Island is sampled by nearnadir CrIS scans, where horizontal resolution is best (see Fig. 3b). Unsmoothed $T_{B_{i}}^{\prime}$ in left panels of Fig. 17 resolve a highly structured wave field over the South Island, with small-scale waves of large amplitude aligned both parallel and orthogonal to the long axis of the terrain, superimposed within a larger-scale wave with phase fronts aligned perpendicular to the terrain long axis. Bramberger et al. (2017) noted similar multiscale horizontal structure in wave fields imaged in $\mathrm{OH}$ airglow at $\sim 87 \mathrm{~km}$ from the NGV. Right panels of Fig. 17 show the same maps after $3 \times 3$ FOV smoothing, which suppresses small-scale wave structure, revealing the largerscale wave response and trailing-wave structure to the southeast of the terrain. This case reveals how the superior noise characteristics of CrIS $15 \mu \mathrm{m}$ channels can provide additional gravity wave information in cases where horizontal wavelengths are small and winds are weak so that waves attain small $\lambda_{z}$, making them difficult to detect in AIRS $15 \mu \mathrm{m}$ channels.

\section{2) GRAVITY WAVES AWAY FROM THE SOUTH ISLAND}

Figure 18 summarizes 6 examples of NGV flights designed to observe deep gravity wave activity far from Christchurch. Figure 18a shows AIRS $T_{B_{i}}^{\prime}$ for one of the two DEEPWAVE NGV flights to sample wave activity around Tasmania. While the overpass geometry was not optimal, it reveals clear trailing gravity wave structure at $2 \mathrm{hPa}$ that was intercepted by the NGV flight plan. Other panels in Fig. 18 show five other NGV flights primarily designed to intercept deep nonorographic gravity waves over the Southern Ocean. With the possible exception of RF17, all reveal a flight plan that intercepted intense deep nonorographic gravity wave observed by AIRS, directly validating the flight-planning strategy to forecast and intercept these waves, as described in section $4 a$.

\section{Conclusions}

While AIRS STND radiances have been used for many years in stratospheric gravity wave research, this study has documented first use of two operational radiance products for near-real-time nowcasting of gravity waves to inform NGV flight planning during DEEPWAVE. Gravity waves in AIRS NRT radiances were correlated at $>99 \%$ with science-quality STND radiances at $15 \mu \mathrm{m}$ throughout DEEPWAVE, validating their use in gravity wave nowcasting. Operational $15-\mu \mathrm{m}$ CrIS radiances, used as a backup to AIRS NRT radiances during DEEPWAVE, also captured gravity wave perturbations accurately: to our knowledge this is the first published study to demonstrate the ability of CrIS to 


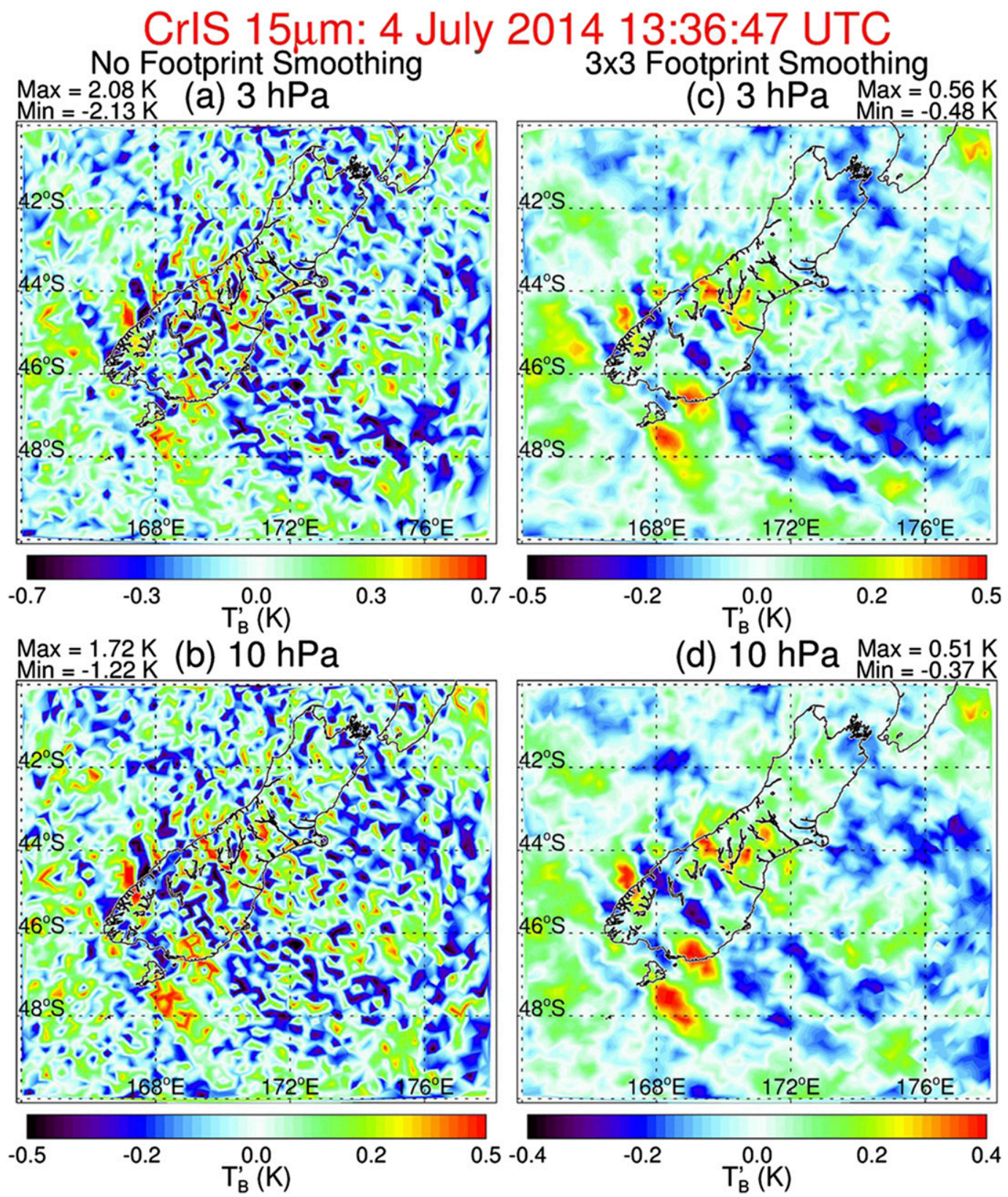

FIG. 17. CrIS $T_{B_{i}}^{\prime}$ from the descending overpass of the South Island on $4 \mathrm{Jul}$ in the (a) 3 and (b) $10 \mathrm{hPa}$ $15 \mu \mathrm{m}$ channels. Adjacent plots to the right show same imagery after application of $3 \times 3$ FOV smoothing alongand cross-track.

observe stratospheric gravity waves at either 15 or $4.3 \mu \mathrm{m}$. Although its wider $15 \mu \mathrm{m}$ spectral bandwidths diminish vertical resolution relative to AIRS (Figs. 1 and 2), CrIS radiances have lower noise levels than AIRS at $15 \mu \mathrm{m}$, allowing CrIS to observe waves at or below AIRS detection thresholds (see Fig. 17). Given this proof of concept, the subsequent launch of a second CrIS on NOAA-20 (Zhou et al. 2016) now provides two CrIS sensors to observe stratospheric gravity waves for operational applications and scientific research.

Our postmission analysis validated the decision to use $15 \mu \mathrm{m}$ rather than $4.3 \mu \mathrm{m}$ gravity wave products for operational DEEPWAVE applications. Time series of $\sigma_{T_{B_{j}}}$ (Fig. 9) revealed a large diurnal variation at $4.3 \mu \mathrm{m}$, absent at $15 \mu \mathrm{m}$ (Fig. 10b), which we traced to large changes in $4.3 \mu \mathrm{m}$ RT between day and night that modify temperature kernel functions and lead 
$\operatorname{Min}=-1.35 \mathrm{~K}$ RF6: 18 June 2014

(a) $2.5 \mathrm{hPa}$ (Descending 1612 UTC)

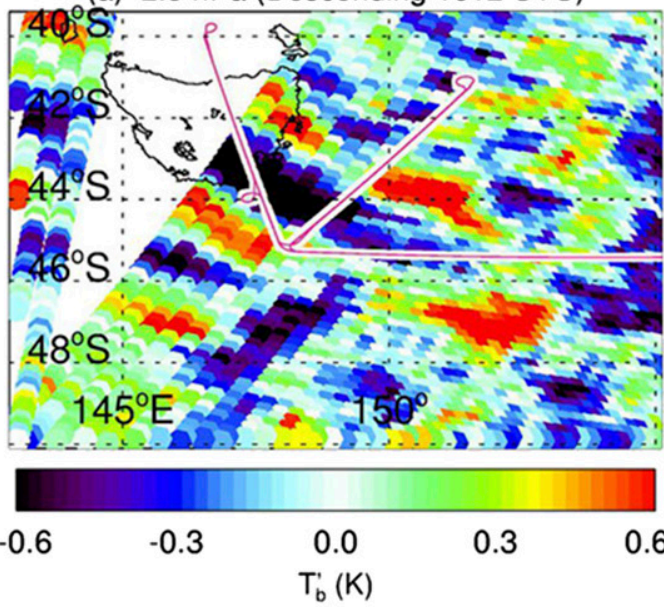

$\operatorname{Min}=-1.89 \mathrm{~K}$ RF18: 7 July 2014

(c) $2 \mathrm{hPa}$ (Descending 1325 UTC)
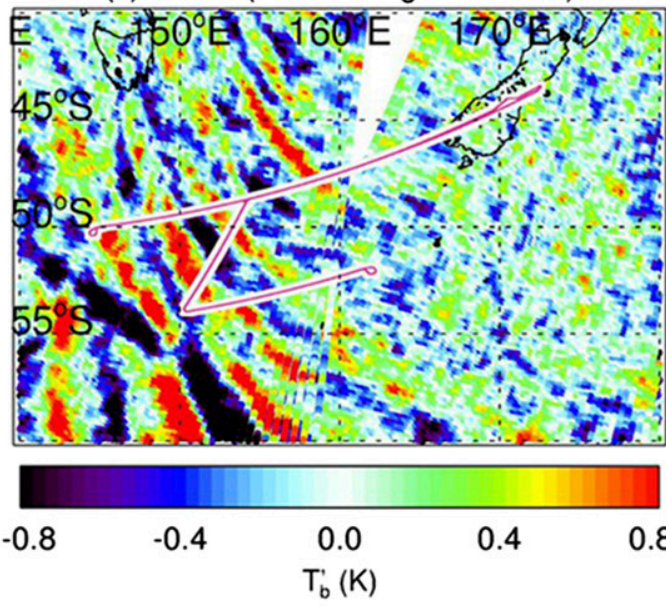

Min $=-1.61$ K RF24: 15 July 2014

(e) $2 \mathrm{hPa}$ (Descending 1414 UTC)
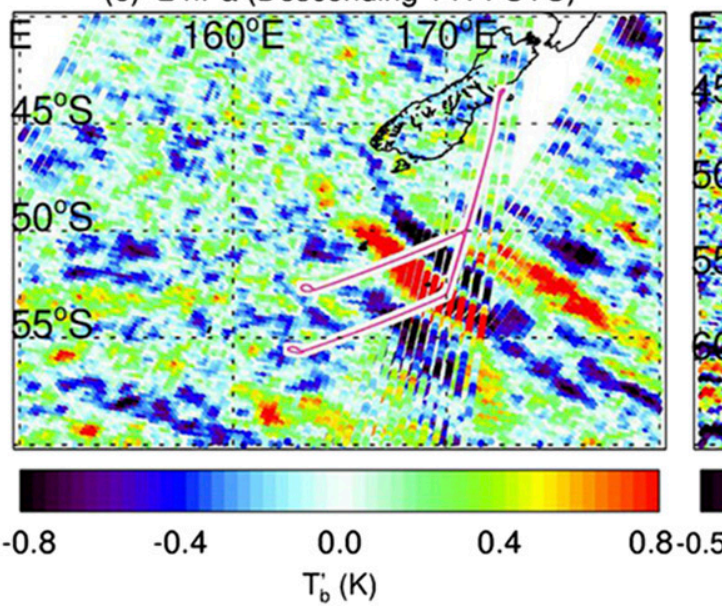

RF17: 5 July $2014 \mathrm{Min}=-1.02 \mathrm{~K}$ (b) $2 \mathrm{hPa}$ (Descending 1337 UTC)

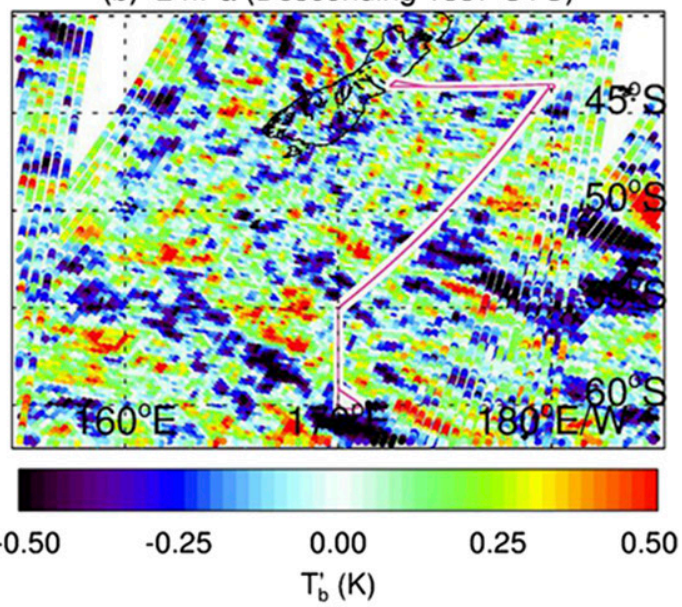

RF19: 8 July $2014 \mathrm{Min}=-1.14 \mathrm{~K}$ (d) $3 \mathrm{hPa}$ (Descending 1408 UTC)

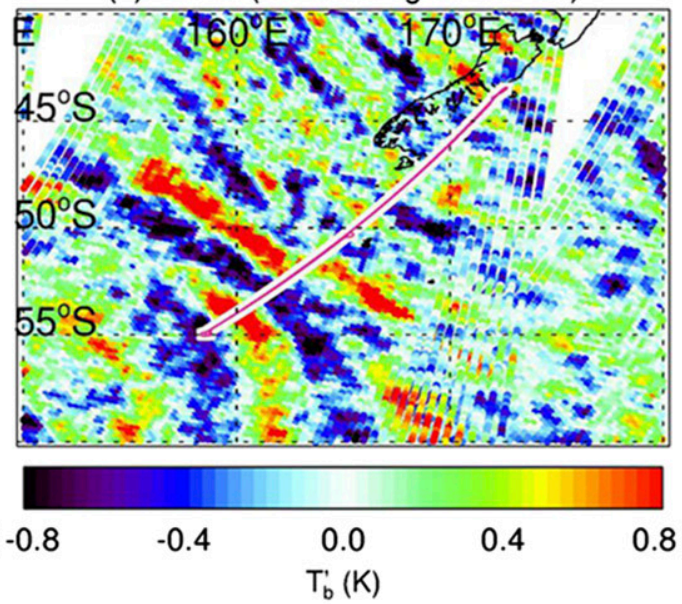

RF25: 18 July $2014_{\mathrm{Min}=-1.38 \mathrm{~K}}^{\mathrm{Ma}}$ (f) $10 \mathrm{hPa}$ (Descending 1307 UTC)

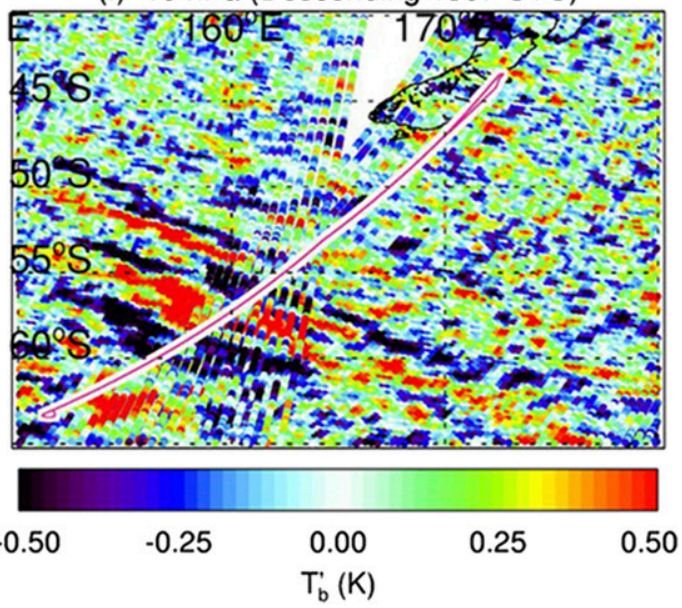

FIG. 18. Deep gravity waves observed by the NGV away from the South Island during DEEPWAVE, as imaged by AIRS in the indicated $15 \mu \mathrm{m}$ channel. Overpass times are with respect to (a) Hobart and with respect to Christchurch in all other panels. Pink-white curves show the NGV research flight on each day. 
to a purely RT-induced diurnal variation in gravity waveinduced $\sigma_{T_{B_{j}}}$ at $4.3 \mu \mathrm{m}$ (Figs. 10b and 11c). In addition, the hot spot of deep orographic gravity wave activity observed over the South Island during DEEPWAVE was substantially underresolved at $4.3 \mu \mathrm{m}$ (Gisinger et al. 2017; see also Fig. 12) due to broad kernel functions with diminished sensitivity to short $-\lambda_{z}$ waves. By contrast, $15 \mu \mathrm{m}$ products resolved a prominent South Island hot spot in June and July at most altitudes (see Fig. 12), but also revealed that deep orographic gravity wave activity over Tasmania was unusually suppressed during the DEEPWAVE austral winter.

Our operational gravity wave products informed NGV flight planning in a variety of ways during DEEPWAVE. By validating gravity wave forecasts far upstream of the DEEPWAVE RAO on days prior (Fig. 8), the science team gained confidence in specific forecasts, in turn allowing the team to devise and progressively refine NGV flight plans to intercept specific waves as forecast source regions moved into flight range. This strategy led to successful intercepts of orographic gravity waves over Tasmania and nonorographic gravity waves across the Southern Ocean (Figs. 8 and 18). Nearer to home, operational $T_{B_{j}}^{\prime}$ maps provided NRT validation of the NGV flight patterns used to intercept deep orographic gravity waves over the South Island (see Figs. 15 and 17).

As shown in Figs. 12-16, background winds controlled the amplitude of gravity wave-induced $T_{B_{j}}^{\prime}$ responses via refractive changes to gravity wave vertical wavelengths $\lambda_{z}$ (see appendix B). Future work should explore ways to take this important effect into account in more automated operational ways to improve guidance to flight planners and forecasters (e.g., Hoffmann et al. 2016). Simple methods could involve continuous monitoring of forecast wind speed profiles over regions of interest (e.g., as in Fig. 16). More sophisticated approaches could involve forward modeling of three-dimensional prognostic wave fields from forecast models using the kernel functions in Fig. 2 to provide a corresponding $T_{B_{j}}^{\prime}$ forecast (see, e.g., Eckermann et al. 2006; Kruse et al. 2016).

An interesting question raised by this work is whether this gravity wave information contained in operational AIRS and CrIS radiances can be assimilated into operational NWP analyses to improve NWP-model forecasts of gravity waves and gravity wave-driven circulations. As discussed by Eckermann et al. (2018), while AIRS and CrIS radiances are assimilated operationally by most NWP centers (e.g., Hoffmann et al. 2017), most if not all of the gravity wave information they contain is lost at present during the assimilation process. For example, radiances are thinned or averaged prior to assimilation, assimilation is performed at a coarser inner-loop resolution, and static error covariances impose both broad correlation scales that spread observational increments spatially and geostrophic balance constraints that are inappropriate for unbalanced (divergent) gravity wave motion.

The gravity waves explicitly resolved in meteorological analyses must therefore originate almost entirely from model-generated waves in high-resolution forecast backgrounds that cycle continuously through the outer loop without significant observational correction (see Eckermann et al. 2014). It is therefore surprising that gravity wave spatial structure (e.g., wavelengths, phase lines) in high-resolution operational analysis has often been found, both during DEEPWAVE and in other studies, to compare remarkably well with observations, even though wave amplitudes are grossly underestimated (Schroeder et al. 2009; Jewtoukoff et al. 2015; Fritts et al. 2016; Ehard et al. 2017; Hoffmann et al. 2017; Rapp et al. 2018). Since data assimilation provides tight observations-based constraints on the large-scale atmosphere within which model-generated gravity waves are forced, propagate, and refract, which are the primary processes controlling their wavelengths and phases, then it appears that data assimilation currently provides indirect observational constraints on these aspects of gravity waves in these analyses. By contrast, gravity wave amplitudes are likely underestimated by enhanced numerical diffusion near the grid scales of the forecast model (Skamarock 2004) and underresolved sources such as orography (Rutt et al. 2006). Since these amplitude deficiencies are never corrected via direct assimilation of observational gravity wave information, these attenuated forecast gravity waves are simply mirrored in the analysis.

Since gravity wave spatial structure in forecast backgrounds appears to be reproducible and predictable (see, e.g., Figs. 6-8), future high-resolution ensemblebased data assimilation algorithms (e.g., Ha et al. 2017) should eventually be capable of capturing this reproducible gravity wave structure within ensemble-based flow covariances. This would in turn permit direct and accurate assimilation of gravity wave information provided by sensors such as AIRS and CrIS, leading to observational gravity wave increments that correct errors in forecast gravity wave properties directly: for example, by increasing their currently underestimated amplitudes.

Acknowledgments. AIRS NRT and STND gravity wave products as well as weather and flight-planning reports from both the dry run and field campaign are archived and publicly available at http://catalog.eol.ucar.edu/ deepwave_2013 and http://catalog.eol.ucar.edu/deepwave, thanks to NCAR/EOL under the sponsorship of the National Science Foundation. This work was made 
possible by rapid continuous access to NRT AIRS radiances generated via the LANCE at GES DISC through NASA's Earth Science Data and Information System (ESDIS) Project, funded by NASA/HQ. NRL authors acknowledge support of the Chief of Naval Research via the base 6.1 and platform support programs.

\section{APPENDIX A}

\section{Radiance Data Processing and RT Modeling}

For DEEPWAVE, we sought a detailed definition of the gravity wave detection properties of $T_{B}$ swath imagery for each channel and sensor. For their $4.3 \mu \mathrm{m}$ AIRS channels, Hoffmann and Alexander (2009) performed numerical experiments in which a small temperature perturbation was added to a reference profile at a given height and then passed through a forward RT model, a calculation repeated for perturbations inserted at different heights to accumulate radiance sensitivities to temperature perturbations as a function of height, which they used as their kernel functions defining sensitivity to gravity wave perturbations. Hoffmann et al. (2017) performed similar calculations for a subset of $15 \mu \mathrm{m}$ AIRS channels. For our DEEPWAVE AIRS and CrIS channels, we performed an essentially equivalent calculation by utilizing the tangent linear and adjoint components of the Community Radiative Transfer Model (CRTM; Liu and Weng 2013) to derive kernel functions $\mathscr{K}_{i}(z)$ as the Jacobian term $\partial T_{B_{i}} / \partial T$ quantifying the linearized CRTM response of brightness temperature in channel $i$ to small atmospheric temperature perturbations at a given altitude. In deriving these CRTM Jacobians we used background profiles of temperature, ozone and water vapor mixing ratio derived by averaging high-altitude Navy reanalysis fields of Eckermann et al. (2009b) over various DEEPWAVE areas of interest (see Fig. 4) for the months June-July and years 2007-09 inclusive. Representative carbon dioxide profiles in these regions and months were based on the observations of Beagley et al. (2010). The resulting mean profiles were reinterpolated onto a 500-level vertical grid with constant pressure height spacing $(\sim 200 \mathrm{~m})$ extending from the surface to $0.001 \mathrm{hPa}$ for use in the CRTM. The $\mathscr{K}_{i}(z)$ computed for DEEPWAVE used mean Navy reanalysis profiles over the South Island of New Zealand $\left(41^{\circ}-47^{\circ} \mathrm{S}, 166^{\circ}-174^{\circ} \mathrm{E}\right)$. For $15 \mu \mathrm{m}$ channels, the resulting $\mathscr{K}_{i}(z)$ profiles in Figs. 1 and 2 have similar shapes and peaks to conventional weighting functions derived from absorption and optical depth profiles calculated using the standard CRTM forward model (this is not true at $4.3 \mu \mathrm{m}$; see Yin 2016).

\section{a. AIRS}

Following Gong et al. (2012) and Eckermann and Wu (2012), using (2) we coherently averaged brightness temperatures $T_{B}$ from a subset of $5015 \mu \mathrm{m}$ AIRS channels into a set of $j=1 \ldots 12$ noise-reduced $T_{B}$ scenes, peaking at a range of levels from $\sim 2 \mathrm{hPa}(j=1)$ to $\sim 100 \mathrm{hPa}$ $(j=12)$, as summarized in Table A1. Two $\beta$ channels in Table A1 isolate low-frequency channels where weighting functions are noticeably different (narrower) to higher-frequency channels that peak near the same altitudes (see Fig. 3 of Eckermann et al. 2009a).

\section{b. $C r I S$}

CrIS uses a Fourier transform spectrometer (FTS) to acquire radiances $R_{\nu_{i}}$, which, in standard operations mode, are issued within 1305 infrared (IR) channels spanning three bands: a 713-channel $650-1095 \mathrm{~cm}^{-1}$ longwave IR band $(9.13-15.38 \mu \mathrm{m})$, a 433 -channel $1210-1750 \mathrm{~cm}^{-1}$ midwave IR band $(5.71-8.26 \mu \mathrm{m})$, and a 159 -channel $2155-2550 \mathrm{~cm}^{-1}$ shortwave IR band $(3.92-4.64 \mu \mathrm{m})$. To suppress sidelobe contamination of channel radiances by the FTS spectral response function (SRF), we applied a spectral Hamming apodization as described in Han et al. (2015) to the L1B radiances. While other functions have better sidelobe suppression properties, they achieve this at the expense of spectral resolution (Barnet et al. 2000). For our gravity wave application, the Hamming apodization provides an acceptable trade-off between suppressing side lobes without excessively compromising the spectral resolution needed for altitude discrimination, while also reducing noise (Han et al. 2015) to aid gravity wave detection.

Based on inspection of individual channel kernel functions, Table A2 lists the 34 CrIS channels we selected and, in some cases coherently averaged, to yield a set of 10 mean $T_{B_{j}}$ scenes. Some spectral regions that we used for AIRS could not be used for CrIS, since the wider CrIS bandwidths led to kernel functions that peaked at both lower and upper stratospheric altitudes (e.g., AIRS channel 74 and CrIS channel 29 near $667.5 \mathrm{~cm}^{-1}$ ). Following the selection of lower-frequency $\beta$ channels for AIRS, for CrIS we also created a $6 \beta$ channel from 7 low-frequency channels, for comparison with our standard channel 6 , derived by averaging 9 higher-frequency channels. For both AIRS and CrIS $\beta$ channels, we found that somewhat narrower kernel functions were offset by higher noise levels, making them on the whole inferior to our standard high-frequency channels for gravity wave detection.

\section{c. Isolating gravity wave radiance perturbations}

For each CrIS scan, we unwrapped the 9 FOV measurements within the 30 FOR ellipses to form three 
TABLE A1. The 50 individual AIRS $15 \mu \mathrm{m}$ channels averaged into 12 mean $T_{B_{j}}$ scenes spanning the stratosphere from 100 to $2 \mathrm{hPa}$.

\begin{tabular}{|c|c|c|c|c|c|}
\hline $\begin{array}{l}\text { Mean channel } \\
\quad \text { No. } j\end{array}$ & $\begin{array}{c}\text { Pressure } \\
\text { peak }(\mathrm{hPa})\end{array}$ & $\begin{array}{c}\text { Pressure } \\
\text { height }(\mathrm{km})\end{array}$ & $\begin{array}{l}\text { No. of AIRS } \\
\text { channels } n_{j}^{\text {tot }}\end{array}$ & AIRS channel No. $i(n)$ & $\nu_{i}\left(\mathrm{~cm}^{-1}\right)$ \\
\hline 1 & 2 & 43.5 & 1 & 74 & 667.530 \\
\hline 2 & 2.5 & 42.0 & 1 & 75 & 667.782 \\
\hline 3 & 3 & 40.5 & 1 & 76 & 668.035 \\
\hline 4 & 4 & 38.5 & 1 & 77 & 668.288 \\
\hline 5 & 7 & 35.0 & 1 & 78 & 668.541 \\
\hline 6 & 10 & 32.0 & 1 & 79 & 668.795 \\
\hline 7 & 20 & 27.0 & 2 & 81,82 & $669.302,669.556$ \\
\hline 8 & 30 & 24.5 & 6 & $102,108,114,120,125,126$ & $\begin{array}{c}674.680,676.233,677.794,679.362 \\
680.675,680.938\end{array}$ \\
\hline $8 \beta$ & 30 & 24.5 & 1 & 72 & 667.025 \\
\hline 9 & 40 & 22.5 & 7 & $64,88,90,94,100,106,118$ & $\begin{array}{c}665.015,671.085,671.596,672.621 \\
674.164,675.715,678.839\end{array}$ \\
\hline $9 \beta$ & 40 & 22.5 & 1 & 71 & 666.773 \\
\hline 10 & 60 & 19.5 & 9 & $66,68,70,86,87,91,93,97,130$ & $\begin{array}{c}665.516,666.018,666.521,670.575 \\
670.830,671.852,672.364 \\
673.392,681.993\end{array}$ \\
\hline 11 & 80 & 17.5 & 14 & $\begin{array}{c}92,98,104,105,110,111,116,117 \\
122,123,128,129,134,140\end{array}$ & $\begin{array}{c}672.108,673.649,675.197,675.456, \\
676.753,677.013,678.316,678.577, \\
679.887,680.149,681.465,681.729, \\
688.410,690.033\end{array}$ \\
\hline 12 & 100 & 16.0 & 6 & $132,133,138,139,149,152$ & $\begin{array}{c}687.871,688.140,689.491,689.762 \\
692.482,693.302\end{array}$ \\
\hline
\end{tabular}

equivalent AIRS-like single cross-track scans each containing 90 FOVs, consisting of FOVs $1-3,4-6$, and 7-9. As illustrated in Fig. 3, this yields parallel crosstrack data near nadir, but a more irregular zig-zag sampling of longitude and latitude at far off-nadir scan angles. This unwrapping procedure allowed us to use the same algorithms described below to isolate gravity wave perturbations from both AIRS and CrIS swath radiances.

To isolate gravity perturbations $T_{B_{i}}^{\prime}$, we fitted a largescale background $\bar{T}_{B_{j}}$ as follows. After linearly interpolating any limited missing FOV data along the swath, we performed a 33 -point $(\sim 400 \mathrm{~km})$ along-track running average along all the available global push-broom swath imagery for a given day. Using these smoothed radiances, we then fitted each scan of 90 cross-track data points to a sixth-order polynomial as a function of scan angle, to account for cross-track asymmetries, stratospheric limb brightening, and other systematic trends. The radiances from these individual cross-track fits were then smoothed using a 15-point running average in the along-track direction, then subtracted from the raw radiances to isolate perturbations

$$
T_{B_{j}}^{\prime}=T_{B_{j}}-\bar{T}_{B_{j}}
$$

in swath imagery with horizontal wavelengths $\$ 500 \mathrm{~km}$. Edge effects in these fitting and averaging procedures prevent effective extraction of wave signals at the far off-nadir scan angles at the outside edges of the swath (where, due to larger measurement footprints, there is often diminished sensitivity to gravity waves relative to nadir views; see, e.g., Eckermann and Wu 2006).

For AIRS, as discussed in section 3 , additional $3 \times$ 3 FOV smoothing of $T_{B_{j}}^{\prime}$ along and cross track was sometimes necessary in certain $15 \mu \mathrm{m}$ channels to reduce background noise and reveal clearer gravity wave signals, with resultant suppression of resolved gravity waves in the $\lambda_{h} \sim 30-100 \mathrm{~km}$ band. Such smoothing was not needed in CrIS $15 \mu \mathrm{m}$ products or in the $4.3 \mu \mathrm{m}$ products, given lower noise levels.

\section{APPENDIX B}

\section{Gravity Wave Visibility Functions}

Consider an instantaneous three-dimensional field of gravity wave temperature perturbations $T^{\prime}\left(x, y, z, t_{0}\right)$ that AIRS or CrIS observes at time $t_{0}$. The anticipated radiance perturbations in any channel $j$ can be estimated by the forward-model calculation (e.g., Eckermann and $\mathrm{Wu} 2006$ )

$$
T_{B_{j}}^{\prime}(x, y)=\int_{0}^{\infty} \mathscr{K}_{j}(Z) T^{\prime}\left(x, y, Z, t_{0}\right) d Z
$$

A better calculation includes horizontal averaging due to finite sizes of measurement footprints, and a 
TABLE A2. The 34 individual CrIS $15 \mu \mathrm{m}$ channels averaged into 10 mean $T_{B_{i}}$ scenes spanning the stratosphere from 100-3 hPa.

\begin{tabular}{cccccc}
\hline $\begin{array}{c}\text { Mean channel } \\
\text { No. } j\end{array}$ & $\begin{array}{c}\text { Pressure } \\
\text { peak (hPa) }\end{array}$ & $\begin{array}{c}\text { Pressure } \\
\text { height }(\mathrm{km})\end{array}$ & $\begin{array}{c}\text { No. of CrIS } \\
\text { channels } n_{j}^{\text {tot }}\end{array}$ & CrIS channel No. $i(n)$ & $\nu_{i}\left(\mathrm{~cm}^{-1}\right)$ \\
\hline 1 & 3 & 40.5 & 1 & 30 & 668.125 \\
2 & 10 & 32.0 & 1 & 31 & 668.750 \\
3 & 20 & 27.0 & 1 & 32 & 669.375 \\
4 & 30 & 24.5 & 1 & 33 & 670.000 \\
5 & 40 & 22.5 & 2 & 21,22 & $662.500,663.125$ \\
6 & 50 & 21.0 & 9 & $34,35,38,40,42,43,45,48,50$ & $671.250,671.875,673.750,675.000$, \\
& & & & & $676.250,676.875,678.125$, \\
$6 \beta$ & 55 & 20.5 & 7 & $10,11,14,16,17,26,27$ & $680.000,681.250$ \\
& & & & & $655.625,656.250,658.125,659.375$, \\
7 & 60 & 19.5 & 4 & $36,49,51,53$ & $660.000,665.625,666.250$ \\
8 & 80 & 17.5 & 4 & $59,60,61,63$ & $671.875,680.000,681.250,682.500$ \\
9 & 100 & 16.0 & 4 & $67,68,69,71$ & $686.250,686.875,687.500,688.750$ \\
& & & & & $691.250,691.875,692.500,693.750$ \\
\hline
\end{tabular}

background $\bar{T}(x, y, z)$ to compute total swath radiance using full forward RT. In this case background radiance is fitted and removed using identical algorithms to appendix A, section c (see, e.g., Eckermann and Wu 2006; Eckermann et al. 2006). A series of such calculations using input wave fields of different (constant) horizontal and vertical wavelength, $\lambda_{h}$ and $\lambda_{z}$, respectively, and constant arbitrary amplitude $\hat{T}$ maps out anticipated brightness temperature amplitudes $\hat{T}_{B_{j}}$ for waves of given $\lambda_{h}, \lambda_{z}$, and $\hat{T}$.

The broad nature of the kernel functions $\mathscr{K}_{j}(z)$ in Fig. 1 means that the dominant sensitivity is to $\lambda_{z}$. Since (B1) is linear in $\hat{T}$, we can express these results in terms of a normalized sensitivity

$$
\varepsilon_{j}\left(\lambda_{z}\right)=\frac{\hat{T}_{B_{j}}}{\hat{T}},
$$

such that $0<\varepsilon_{j}\left(\lambda_{z}\right)<1$, whereupon $\hat{T}_{B_{j}}=\varepsilon_{j}\left(\lambda_{z}\right) \hat{T}$ for a gravity wave of arbitrary $\lambda_{z}$ and $\hat{T}$.

Eckermann and $\mathrm{Wu}(2006)$ showed that in many cases the visibility functions $\varepsilon_{j}$ can be accurately approximated spectrally as

$$
\tilde{\varepsilon}_{j}\left(\lambda_{z}\right)=\frac{\left|\tilde{\mathscr{K}}_{j}(M)\right|}{\left|\tilde{\mathscr{K}}_{j}(0)\right|},
$$

where $M=2 \pi / \lambda_{z}$ and $\tilde{\mathscr{K}}_{j}(M)$ is the Fourier Transform of $\mathscr{K}_{j}(z)$, a result that follows directly from the definition (B1) for input wave parameters of constant amplitude and wavelength.

When these calculations yield a $\hat{T}_{B_{j}} \leqslant \Delta T_{B_{i}}^{\mathrm{NEDT}}$, where the noise-equivalent delta temperature, $\Delta T_{B_{j}}^{\mathrm{NEDT}}$, quantifies the channel noise floor, then the wave will be invisible since it produces perturbations below channel noise levels.

\section{REFERENCES}

Alexander, M. J., and C. Barnet, 2007: Using satellite observations to constrain parameterizations of gravity wave effects for global models. J. Atmos. Sci., 64, 1652-1665, https://doi.org/ 10.1175/JAS3897.1.

_ , and Coauthors, 2010: Recent developments in gravity-wave effects in climate models and the global distribution of gravitywave momentum flux from observations and models. Quart. J. Roy. Meteor. Soc., 136, 1103-1124, https://doi.org/10.1002/ QJ.637.

Andreassen, Ø., P. Ø. Hvidsten, D. C. Fritts, and S. Arendt, 1998: Vorticity dynamics in a breaking internal gravity wave. Part 1. Initial instability evolution. J. Fluid Mech., 367, 27-46, https:// doi.org/10.1017/S0022112098001645.

Aumann, H. H., and Coauthors, 2003: AIRS/AMSU/HSB on the Aqua mission: Design, science objectives, data products, and processing systems. IEEE Trans. Geosci. Remote Sens., $\mathbf{4 1}$ 253-264, https://doi.org/10.1109/TGRS.2002.808356.

Barnet, C. D., J. M. Blaisdell, and J. Susskind, 2000: Practical methods for rapid and accurate computation of interferometric spectra for remote sensing applications. IEEE Trans. Geosci. Remote Sens., 38, 169-183, https://doi.org/10.1109/ 36.823910 .

Beagley, S. R., C. D. Boone, V. I. Fomichev, J. J. Jin, K. Semeniuk, J. C. McConnell, and P. F. Bernath, 2010: First multi-year occultation observations of $\mathrm{CO}_{2}$ in the MLT by ACE satellite: Observations and analysis using the extended CMAM. Atmos. Chem. Phys., 10, 1133-1153, https://doi.org/10.5194/ acp-10-1133-2010.

Bossert, K., and Coauthors, 2015: Momentum flux estimates accompanying multiscale gravity waves over Mount Cook, New Zealand, on 13 July 2014 during the DEEPWAVE campaign. J. Geophys. Res. Atmos., 120, 9323-9337, https:// doi.org/10.1002/2015JD023197.

_ C. G. Kruse, C. J. Heale, D. C. Fritts, B. P. Williams, J. B. Snively, P.-D. Pautet, and M. J. Taylor, 2017: Secondary gravity wave generation over New Zealand during the DEEPWAVE campaign. J. Geophys. Res. Atmos., 122, 7834-7850, https:// doi.org/10.1002/2016JD026079.

Bramberger, M., and Coauthors, 2017: Does strong tropospheric forcing cause large-amplitude mesospheric gravity waves? A DEEPWAVE case study. J. Geophys. Res. Atmos., 122, $11422-$ 11 443, https://doi.org/10.1002/2017JD027371. 
Chen, Y., Y. Han, P. van Delst, and F. Weng, 2013: Assessment of shortwave infrared sea surface reflection and nonlocal thermodynamic equilibrium effects in the Community Radiative Transfer Model using IASI data. J. Atmos. Oceanic Technol., 30, 2152-2160, https://doi.org/10.1175/ JTECH-D-12-00267.1.

DeSouza-Machado, S. G., L. L. Strow, S. E. Hannon, H. E. Motteler, M. López-Puertas, B. Funke, and D. P. Edwards, 2007: Fast forward radiative transfer modeling of $4.3 \mu \mathrm{m}$ nonlocal thermodynamic equilibrium effects for infrared temperature sounders. Geophys. Res. Lett., 34, L01802, https://doi.org/ 10.1029/2006GL026684.

Doyle, J. D., Q. Jiang, R. B. Smith, and V. Grubišić, 2011: Threedimensional characteristics of stratospheric mountain waves during T-REX. Mon. Wea. Rev., 139, 3-23, https://doi.org/ 10.1175/2010MWR3466.1.

Eckermann, S. D., and P. Preusse, 1999: Global measurements of stratospheric mountain waves from space. Science, 286, 1534 1537, https://doi.org/10.1126/science.286.5444.1534.

— and D. L. Wu, 2006: Imaging gravity waves in lower stratospheric AMSU-A radiances, Part 1: Simple forward model. Atmos. Chem. Phys., 6, 3325-3341, https://doi.org/10.5194/ acp-6-3325-2006.

— , and - 2012: Satellite detection of orographic gravity-wave activity in the winter subtropical stratosphere over Australia and Africa. Geophys. Res. Lett., 39, L21807, https://doi.org/ 10.1029/2012GL053791.

— , and Coauthors, 2006: Imaging gravity waves in lower stratospheric AMSU-A radiances, Part 2: Validation case study. Atmos. Chem. Phys., 6, 3343-3362, https://doi.org/10.5194/ acp-6-3343-2006.

— L. Loffmann, M. Höpfner, D. L. Wu, and M. J. Alexander, 2009a: Antarctic NAT PSC belt of June 2003: Observational validation of the mountain wave seeding hypothesis. Geophys. Res. Lett., 36, L02807, https://doi.org/10.1029/ 2008 GL036629.

—_, and Coauthors, 2009b: High-altitude data assimilation system experiments for the northern summer mesosphere season of 2007. J. Atmos. Sol.-Terr. Phys., 71, 531-551, https://doi.org/ 10.1016/j.jastp.2008.09.036.

— J. P. McCormack, J. Ma, T. F. Hogan, and K. A. Zawdie, 2014: Stratospheric analysis and forecast errors using hybrid and sigma coordinates. Mon. Wea. Rev., 142, 476-485, https:// doi.org/10.1175/MWR-D-13-00203.1.

__ and Coauthors, 2016: Dynamics of orographic gravity waves observed in the mesosphere over the Auckland Islands during the Deep Propagating Gravity Wave Experiment (DEEPWAVE). J. Atmos. Sci., 73, 3855-3876, https://doi.org/ 10.1175/JAS-D-16-0059.1.

— , and Coauthors, 2018: High-altitude $(0-100 \mathrm{~km})$ global atmospheric reanalysis system: Description and application to the 2014 austral winter of the Deep Propagating Gravity Wave Experiment (DEEPWAVE). Mon. Wea. Rev., 146, 2639-2666, https://doi.org/10.1175/MWR-D-17-0386.1.

Ehard, B., and Coauthors, 2017: Horizontal propagation of large-amplitude mountain waves into the polar night jet. J. Geophys. Res. Atmos., 122, 1423-1436, https://doi.org/10.1002/ 2016JD025621.

Fritts, D. C., and M. J. Alexander, 2003: Gravity wave dynamics and effects in the middle atmosphere. Rev. Geophys., 41, 1003, https://doi.org/10.1029/2001RG000106.

— - and Coauthors, 2016: The Deep Propagating Gravity Wave Experiment (DEEPWAVE): An airborne and ground-based exploration of gravity wave propagation and effects from their sources throughout the lower and middle atmosphere. Bull. Amer. Meteor. Soc., 97, 425-453, https://doi.org/10.1175/ BAMS-D-14-00269.1.

Gelaro, R., and Coauthors, 2017: The Modern-Era Retrospective Analysis for Research and Applications, version 2 (MERRA-2). J. Climate, 30, 5419-5454, https://doi.org/ 10.1175/JCLI-D-16-0758.1.

Gisinger, S., and Coauthors, 2017: Atmospheric conditions during the Deep Propagating Gravity Wave Experiment (DEEPWAVE). Mon. Wea. Rev., 145, 4249-4275, https://doi.org/10.1175/ MWR-D-16-0435.1.

Goldberg, R. A., and Coauthors, 2006: The MaCWAVE program to study gravity wave influences on the polar mesosphere. Ann. Geophys., 24, 1159-1173, https://doi.org/10.5194/ANGEO-241159-2006.

Goldberg, M. D., H. Kilcoyne, H. Cikanek, and A. Mehta, 2013: Joint Polar Satellite System: The United States next generation civilian polar-orbiting environmental satellite system. J. Geophys. Res. Atmos., 118, 13 463-13 475, https://doi.org/ 10.1002/2013JD020389.

Gong, J., D. L. Wu, and S. D. Eckermann, 2012: Gravity wave variances and propagation derived from AIRS radiances. Atmos. Chem. Phys., 12, 1701-1720, https://doi.org/10.5194/ acp-12-1701-2012.

— gravity waves in AIRS images and ECMWF analysis. J. Geophys. Res. Atmos., 120, 2210-2228, https://doi.org/ 10.1002/2014JD022527.

Ha, S., C. Snyder, W. C. Skamarock, J. Anderson, and N. Collins, 2017: Ensemble Kalman filter data assimilation for the Model for Prediction Across Scales (MPAS). Mon. Wea. Rev., 145, 4673-4692, https://doi.org/10.1175/MWR-D-17-0145.1.

Han, Y., and Coauthors, 2013: Suomi NPP CrIS measurements, sensor data record algorithm, calibration and validation activities, and record data quality. J. Geophys. Res. Atmos., 118, 12 734-12 748, https://doi.org/10.1002/2013JD020344.

, L. Suwinski, D. Tobin, and Y. Chen, 2015: Effect of selfapodization correction on Cross-track Infrared Sounder radiance noise. Appl. Opt., 54, 10114-10122, https://doi.org/ 10.1364/AO.54.010114.

Hendricks, E. A., J. D. Doyle, S. D. Eckermann, Q. Jiang, and P. A. Reinecke, 2014: What is the source of the stratospheric gravity wave belt in austral winter? J. Atmos. Sci., 71, 1583-1592, https://doi.org/10.1175/JAS-D-13-0332.1.

Hoffmann, L., and M. J. Alexander, 2009: Retrieval of stratospheric temperatures from Atmospheric Infrared Sounder radiance measurements for gravity wave studies. J. Geophys. Res., 114, D07105, https://doi.org/10.1029/2008JD011241.

$\ldots$, X. Xue, and M. J. Alexander, 2013: A global view of stratospheric gravity wave hotspots located with Atmospheric Infrared Sounder observations. J. Geophys. Res. Atmos., 118, 416-434, https://doi.org/10.1029/2012JD018658.

—-, M. J. Alexander, C. Clerbaux, A. W. Grimsdell, C. I. Meyer, T. Rößler, and B. Tournier, 2014: Intercomparison of stratospheric gravity wave observations with AIRS and IASI. Atmos. Meas. Tech., 7, 4517-4537, https://doi.org/ 10.5194/amt-7-4517-2014.

_- A. W. Grimsdell, and M. J. Alexander, 2016: Stratospheric gravity waves at Southern Hemisphere orographic hotspots: 2003-2014 AIRS/Aqua observations. Atmos. Chem. Phys., 16, 9381-9397, https://doi.org/10.5194/acp16-9381-2016. 
— R. Spang, A. Orr, M. J. Alexander, L. A. Holt, and O. Stein, 2017: A decadal satellite record of gravity wave activity in the lower stratosphere to study polar stratospheric cloud formation. Atmos. Chem. Phys., 17, 2901-2920, https://doi.org/ 10.5194/acp-17-2901-2017.

Horinouchi, T., and Coauthors, 2003: Tropical cumulus convection and upward-propagating waves in middle-atmospheric GCMs. J. Atmos. Sci., 60, 2765-2782, https://doi.org/10.1175/15200469(2003)060<2765:TCCAUW >2.0.CO;2.

Jewtoukoff, V., A. Hertzog, R. Plougonven, A. de la Camara, and F. Lott, 2015: Comparison of gravity waves in the Southern Hemisphere derived from balloon observations and the ECMWF analyses. J. Atmos. Sci., 72, 3449-3468, https:// doi.org/10.1175/JAS-D-14-0324.1.

Jiang, Q., and J. D. Doyle, 2008: On the diurnal variation of mountain waves. J. Atmos. Sci., 65, 1360-1377, https://doi.org/ 10.1175/2007JAS2460.1.

__, _- S. D. Eckermann, and B. P. Williams, 2019: Stratospheric trailing gravity waves from New Zealand. J. Atmos. Sci., 76, 1565-1586, https://doi.org/10.1175/JASD-18-0290.1.

Kaifler, B., N. Kaifler, B. Ehard, A. Dörnbrack, M. Rapp, and D. C. Fritts, 2015: Influences of source conditions on mountain wave penetration into the stratosphere and mesosphere. Geophys. Res. Lett., 42, 9488-9494, https://doi.org/ 10.1002/2015GL066465.

Kim, Y.-J., S. D. Eckermann, and H.-Y. Chun, 2003: An overview of the past, present and future of gravity-wave drag parametrization for numerical climate and weather prediction models. Atmos.-Ocean, 41, 65-98, https://doi.org/10.3137/ ao. 410105 .

Kruse, C. G., R. B. Smith, and S. D. Eckermann, 2016: The midlatitude lower-stratospheric mountain wave "valve layer." J. Atmos. Sci., 73, 5081-5100, https://doi.org/10.1175/JAS-D16-0173.1.

Laursen, K. K., D. P. Jorgensen, G. P. Brasseur, S. L. Ustin, and J. R. Huning, 2006: HIAPER: The next generation NSF/NCAR research aircraft. Bull. Amer. Meteor. Soc., 87, 896-909, https://doi.org/10.1175/BAMS-87-7-896.

Liu, Q., and F. Weng, 2013: Using advanced matrix operator (AMOM) in Community Radiative Transfer Model. IEEE J. Sel. Top. Appl. Earth Obs. Remote Sens., 6, 1211-1218, https://doi.org/10.1109/JSTARS.2013.2247026.

López-Puertas, M., and F. W. Taylor, 1989: Carbon dioxide 4.3- $\mu \mathrm{m}$ emission in the Earth's atmosphere: A comparison between Nimbus 7 SAMS measurements and non-local thermodynamic equilibrium radiative transfer calculations. J. Geophys. Res., 94, 13 045-13 068, https://doi.org/10.1029/JD094iD10p13045.

Lynch, P., and X.-Y. Huang, 2010: Initialization. Data Assimilation: Making Sense of Observations, W. Lahoz, B. Khattatov, and R. Ménard, Eds., Springer, 241-260.

McLandress, C., M. J. Alexander, and D. L. Wu, 2000: Microwave Limb Sounder observations of gravity waves in the stratosphere: A climatology and interpretation. J. Geophys. Res., 105, 11 947-11 967, https://doi.org/10.1029/ 2000JD900097.

Morgenstern, O., and Coauthors, 2017: Review of the global models used within phase 1 of the Chemistry-Climate Model Initiative (CCMI). Geosci. Model Dev., 10, 639-671, https:// doi.org/10.5194/gmd-10-639-2017.

Murphy, K. J., and Coauthors, 2015: LANCE, NASA's Land, Atmosphere Near Real-Time Capability for EOS. TimeSensitive Remote Sensing, C. D. Lippitt, D. A. Stow, and
L. L. Coulter, Eds., 1st ed. Springer, 113-127, https://doi.org/ 10.1007/978-1-4939-2602-2_8.

O'Sullivan, D., and T. J. Dunkerton, 1995: Generation of inertiagravity waves in a simulated life cycle of baroclinic instability. J. Atmos. Sci., 52, 3695-3716, https://doi.org/10.1175/15200469(1995)052<3695:GOIWIA > 2.0.CO;2.

Pagano, T. S., H. H. Aumann, D. E. Hagan, and K. Overoye, 2003: Prelaunch and in-flight radiometric calibration of the Atmospheric Infrared Sounder (AIRS). IEEE Trans. Geosci. Remote Sens., 41, 265-273, https://doi.org/10.1109/ TGRS.2002.808324.

- S. Broberg, H. H. Aumann, D. Elliott, E. Manning, and L. Strow, 2012: Performance status of the Atmospheric Infrared Sounder ten years after launch. Proc. SPIE, 8527, 852703, https://doi.org/10.1117/12.977309.

Parkinson, C. L., 2013: Summarizing the first ten years of NASA's Aqua mission. IEEE J. Sel. Top. Appl. Earth Obs. Remote Sens., 6, 1179-1188, https://doi.org/10.1109/JSTARS.2013.2239608.

Pautet, P.-D., and Coauthors, 2016: Large amplitude mesospheric response to an orographic wave generated over the Southern Ocean Auckland Islands $\left(50.7^{\circ} \mathrm{S}\right)$ during the DEEPWAVE project. J. Geophys. Res. Atmos., 121, 1431-1441, https:// doi.org/10.1002/2015JD024336.

— M. J. Taylor, S. D. Eckermann, and N. Criddle, 2019: Regional distribution of mesospheric small-scale gravity waves during DEEPWAVE. J. Geophys. Res. Atmos., 124, 7069-7081, https:// doi.org/10.1029/2019JD030271.

Portele, T. C., A. Dörnbrack, J. S. Wagner, S. Gisinger, B. Ehard, P.-D. Pautet, and M. Rapp, 2018: Mountain-wave propagation under transient tropospheric forcing: A DEEPWAVE case study. Mon. Wea. Rev., 146, 1861-1888, https://doi.org/ 10.1175/MWR-D-17-0080.1.

Preusse, P., and Coauthors, 2006: Tropopause to mesopause gravity waves in August: Measurement and modeling. J. Atmos. Sol.-Terr. Phys., 68, 1730-1751, https://doi.org/ 10.1016/j.jastp.2005.10.019.

Rapp, M., A. Dörnbrack, and B. Kaifler, 2018: An intercomparison of stratospheric gravity wave potential energy densities from METOP GPS radio occultation measurements and ECMWF model data. Atmos. Meas. Tech., 11, 1031-1048, https:// doi.org/10.5194/amt-11-1031-2018.

Roscoe, H. K., J. D. Shanklin, and S. R. Colwell, 2005: Has the Antarctic vortex split before 2002? J. Atmos. Sci., 62, 581-588, https://doi.org/10.1175/JAS-3331.1.

Rutt, I. C., J. Thuburn, and A. Staniforth, 2006: A variational method for orographic filtering in NWP and climate models. Quart. J. Roy. Meteor. Soc., 132, 1795-1813, https://doi.org/ 10.1256/qj.05.133.

Schroeder, S., P. Preusse, M. Ern, and M. Riese, 2009: Gravity waves resolved in ECMWF and measured by SABER. Geophys. Res. Lett., 36, L10805, https://doi.org/10.1029/2008GL037054.

Shiotani, M., N. Shimoda, and I. Hirota, 1993: Interannual variability of the stratospheric circulation in the southern hemisphere. Quart. J. Roy. Meteor. Soc., 119, 531-546, https://doi.org/10.1002/ qj. 49711951110.

Skamarock, W. C., 2004: Evaluating mesoscale NWP models using kinetic energy spectra. Mon. Wea. Rev., 132, 3019-3032, https:// doi.org/10.1175/MWR2830.1.

Smith, R. B., and Coauthors, 2016: Stratospheric gravity wave fluxes and scales during DEEPWAVE. J. Atmos. Sci., 73 , 2851-2869, https://doi.org/10.1175/JAS-D-15-0324.1.

Vosper, S. B., A. R. Brown, and S. Webster, 2016: Orographic drag on islands in the NWP mountain grey zone. Quart. 
J. Roy. Meteor. Soc., 142, 3128-3137, https://doi.org/ 10.1002/qj.2894.

Wu, D. L., P. Preusse, S. D. Eckermann, J. H. Jiang, M. de la Torre Juarez, L. Coy, and D. Y. Wang, 2006: Remote sounding of atmospheric gravity waves with satellite limb and nadir techniques. Adv. Space Res., 37, 2269-2277, https://doi.org/10.1016/ j.asr.2005.07.031

Yin, M., 2016: Bias characterization of CrIS shortwave temperature sounding channels using fast NLTE model and GFS forecast field. J. Geophys. Res. Atmos., 121, 1248-1263, https:// doi.org/10.1002/2015JD023876.

Zavyalov, V., and Coauthors, 2013: Noise performance of the CrIS instrument. J. Geophys. Res. Atmos., 118, 13 108-13 120, https://doi.org/10.1002/2013JD020457.

Zhou, L., M. Divakarla, and X. Liu, 2016: An overview of the Joint Polar Satellite System (JPSS) science data product calibration and validation. Remote Sens., 8, 139, https://doi.org/10.3390/ rs8020139. 